\title{
Alkynyl Benzoxazines and Dihydroquinazolines as Cysteine Targeting Covalent Warheads and Their Application in Identification of Selective Irreversible Kinase Inhibitors
}

Kirsten McAulay*e, Emily A. Hoyt ${ }^{\dagger}$, Morgan Thomas ${ }^{\nabla}$, Marianne Schimpl ${ }^{\S}$, Michael S. Bodnarchuk, Hilary J. Lewis, Derek Barratt ${ }^{\S}$, Deepa Bhavsar, ${ }^{\ddagger}$ David M. Robinson, Michael J. Deery ${ }^{\ddagger}$, Derek J. Ogg ${ }^{\S, \perp}$, Gonçalo J. L. Bernardes ${ }^{\dagger, \text {,l }}$, Richard A. Ward, Michael J. Waring ${ }^{\dagger \dagger}$ and Jason G. Kettle*

Oncology R\&D, AstraZeneca, Cambridge, CB4 0WG, UK. ${ }^{\ddagger}$ Oncology R\&D, AstraZeneca, Waltham MA 02451, USA. ${ }^{\S}$ Discovery Sciences, R\&D BioPharmaceuticals, AstraZeneca, Cambridge, CB4 0WG, UK. 'Department of Chemistry, University of Cambridge, Cambridge, CB2 1EW, UK. ${ }^{\star}$ Cambridge Centre for Proteomics, Department of Biochemistry, University of Cambridge, Cambridge, CB2 1QW, UK. "Instituto de Medicina Molecular, Faculdade de Medicina de Universidad de Lisboa, Avenida Prof. Egas Moniz, 1649-028 Lisboa, Portugal. "Northern Institute for Cancer Research, Chemistry, School of Natural and Environmental Sciences, Newcastle University, Bedson Building, Newcastle upon Tyne, NE1 7RU, UK.

\footnotetext{
ABSTRACT: With a resurgence in interest in covalent drugs, there is need to identify new moieties capable of cysteine bond formation that are differentiated from commonly employed systems such as acrylamide. Herein, we report on the discovery of new alkynyl benzoxazine and dihydroquinazoline moieties capable of covalent reaction with cysteine. Their utility as alternative electrophilic warheads for chemical biological probes and drug molecules is demonstrated through site-selective protein modification and incorporation into kinase drug scaffolds. A potent covalent inhibitor of JAK3 kinase was identified with superior selectivity across the kinome and improvements in in vitro pharmacokinetic profile relative to the related acrylamide-based inhibitor. In addition, the use of a novel heterocycle as cysteine reactive warhead is employed to target Cys788 in c-KIT where acrylamide has previously failed to form covalent interactions. These new reactive and selective heterocyclic warheads supplement the current repertoire for cysteine covalent modification whilst avoiding some of the limitations generally associated with established moieties.
}

\section{INTRODUCTION}

Targeted covalent inhibitors (TCIs) are designed to bind covalently to poorly conserved amino acids within a biological protein target, effecting a change in biological function. ${ }^{1}$ In contrast to traditional non-covalent inhibitors, TCIs are designed to initially make a reversible interaction with the binding site, followed by covalent bond formation with a reactive protein residue, typically a nucleophilic amino acid. ${ }^{2}$ A number of amino acids including lysine and aspartic acid have been targeted, ${ }^{3}$ however, most commonly, interactions with cysteine are favoured. ${ }^{4}$ In particular, nucleophilic non-catalytic cysteines located within different parts of the ATP binding site of various kinases provide numerous opportunities for irreversible inhibitor development. ${ }^{5} \mathrm{~A}$ recent review by Gray et $a l .{ }^{4}$ has detailed the locations of all cysteines across the human kinome, classifying the accessible cysteines into groups based on their position within the active site. This provides useful information to aid compound design, allowing incorporation of an electrophilic 
group at the appropriate position. ${ }^{6}$ However, placement of an electrophilic group within proximity of an accessible cysteine is not necessarily sufficient to promote a rapid and stable covalent binding interaction. Reaction must be both electronically and sterically favoured, ${ }^{7}$ with the $\mathrm{pK}_{\mathrm{a}}$ of the targeted cysteine also playing a significant role. ${ }^{1}$ Due to the increased strength and often irreversible nature of the covalent bonds formed between a TCI and target, the use of covalent inhibitors offers the potential for increased potency and selectivity as well as prolonged pharmacodynamic effects, and hence, a potential for reduced dose and increased duration of action. ${ }^{8}$ The specific nature of the interaction can also improve selectivity. There are over 40 covalent drugs currently approved by the US FDA; however, only a handful of these covalent interactions have been discovered through rational design. ${ }^{9}$ In recent years, a number of specific covalent kinase inhibitors have been approved: afatinib (2013), ibrutinib (2013), osimertinib (2015), neratinib (2017) and acalabrutinib (2017). ${ }^{3,10,11}$ With the recent success of these drugs there has been renewed interest in the development of TCI's. ${ }^{2,3,8,9,12-15}$ Despite significant effort, the simple acrylamide Michael acceptor remains the most frequently used moiety for cysteine capture due to its ease of synthesis, acceptable reactivity window, selectivity for cysteine over other amino acids and ADMET compatibility. ${ }^{14} \mathrm{~A}$ recent review by Bourne and Zhao reported that $c a .85 \%$ of known cysteine targeting kinase inhibitors had an $\alpha, \beta$ unsaturated carbonyl system as the means of capturing cysteine through Michael addition. ${ }^{3}$

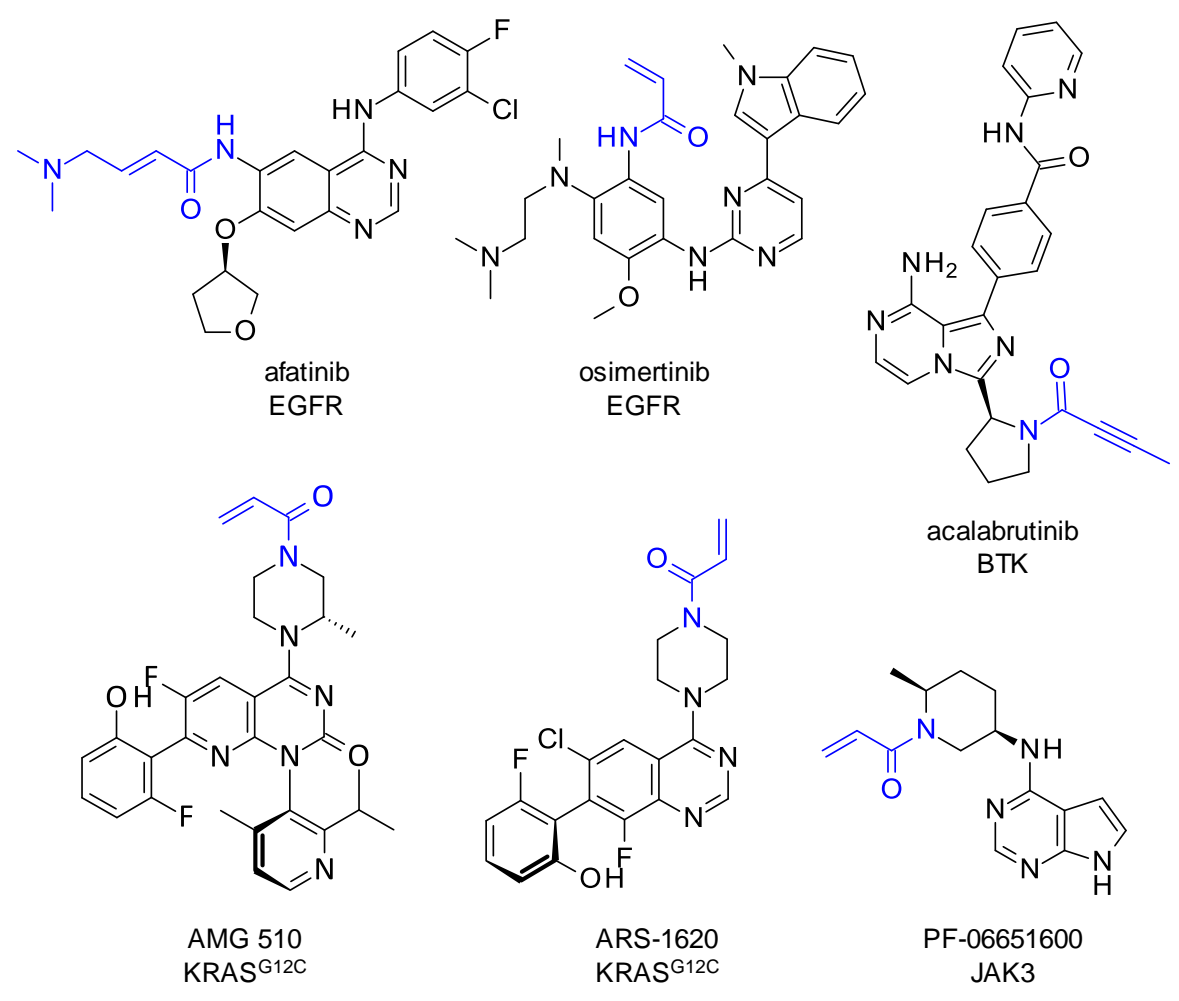

Figure 1. Representative drug scaffolds bearing an $\alpha, \beta$-unsaturated Michael acceptor for covalent reaction with cysteine.

Acrylamide reactivity is greatly influenced by the nature of its connection to the recognition binding element, which in turn is dictated by that which is tolerated based on SAR for the chosen target. Therefore, there remains a significant need for additional cysteine reactive warheads with tuneable properties and reactivity profiles. Novel warheads that can present vectors typically not accessible using acrylamides are of particular interest. Several groups have been working in this area and have recently reported novel methods of cysteine capture. ${ }^{16-21}$ Chen et al. have reported the use of allenamides as bioisosteres of acrylamide in EGFR inhibitors, ${ }^{16}$ whilst latent alkynes have been described for the covalent inhibition of Cathepsin $\mathrm{K} .{ }^{17}$ Moreover, targeting cysteine for the chemical siteselective modification of proteins has become a useful technique for many biological and therapeutic applications. ${ }^{22,23}$ For example, this can be used for the formation of antibody drug conjugates (ADC's) for use in cancer therapy ${ }^{24}$ and requires the use of highly reactive moieties to ensure rapid and selective conversion to the conjugate products. In recent years, the toolbox of reactions for 
cysteine protein modification has greatly increased with many research groups having developed efficient methods. For example, in 2016, Bernardes et al. reported the use of carbonylacrylic reagents for irreversible cysteine selective protein modification and have more recently described the use of quaternized pyridine salts for cysteine capture. ${ }^{25,}{ }^{26}$ Recently, novel divinylpyrimidine linkers have also been developed for selective bioconjugation through re-bridging of reduced disulfide bonds in native antibodies. ${ }^{27}$

In this study, we report our efforts towards the synthesis and evaluation of a series of novel heterocyclic warheads capable of cysteine capture. Reactivity of warhead fragments was assessed using glutathione reactivity and quantum mechanical (QM) calculations. Promising scaffolds were investigated further in protein labelling studies and incorporated into drug scaffolds. Overall, our investigations have shown that electrophilic heterocycles could serve as alternative warheads in chemical biology and medicinal chemistry, with the possibility for improved pharmacokinetic properties over acrylamide matched pairs. Labelling studies have also suggested that our novel warheads have potential application in the field of protein modification. Moreover, we have demonstrated the utility of the benzoxazine warhead for covalent modification where acrylamide has previously failed.

\section{RESULTS AND DISCUSSION}

Exploration of Heterocycle Activity Towards Glutathione. We hypothesized that rigidification of a Michael acceptor-like system through incorporation into a heteroatomic ring would provide functionality which would have a specific vector for nucleophilic cysteine attack, thereby, potentially holding it in the reactive conformation. Initially, 5-membered ring systems bearing electrophilic alkenes were explored. However, these compounds proved to be highly reactive towards glutathione addition and in most cases were unstable even in buffer, rendering them incompatible for incorporation into drug-like systems (Table 1). Glutathione reactivity for marketed drugs can vary greatly depending on the molecular structure, for example, osimertinib and acalabrutinib have half-lives of 121 and 809 minutes towards glutathione respectively under this same protocol. Although there is no ideal value, compounds that are too reactive may be highly cleared and generate non-specific adducts.

Table 1. Half-life of 5-membered heterocycles in the presence of glutathione (GSH) and pH7.4 buffer solution.

\begin{tabular}{|c|c|c|c|}
\hline & 1 & 2 & 3 \\
\hline GSH t $t^{1} / 2(\min )$ & $<0.5$ & $\mathrm{NV}^{*}$ & 8.4 \\
\hline Buffer $\mathrm{t}^{1 / 2}(\mathrm{~min})$ & 2531 & $\mathrm{NV} *$ & $>10000$ \\
\hline
\end{tabular}

Compound concentration $1 \mu \mathrm{M}$ in the presence of $4.6 \mathrm{mM}$ glutathione (GSH) at $37^{\circ} \mathrm{C}$ over 20 hours. Half-life determined using LCMS and first order kinetics from disappearance of parent with verapamil as internal standard. *No visible peak by LCMS.

These results led to a change in strategy whereby more stable, less reactive electrophilic heterocyclic ring systems were sought. Exploration of alternative scaffolds led to the initial discovery of bicyclic compound 5a which was similarly highly reactive and unstable in buffer. Notably, the level of reactivity observed for the cyclized benzoxazine 5a is in stark contrast to the corresponding much less reactive aniline amide $\mathbf{4 a}$ (Table 2). Substitution at both the $\alpha$ and $\beta$ carbons with a methyl group (5b and $\mathbf{5 c}$ ) also gave molecules which were unstable and highly reactive towards glutathione. Comparatively, the uncyclized anilides (4b and $\mathbf{4 c})$ were found to be inert and completely unreactive towards glutathione addition. We attributed the instability of the cyclized systems (5a-c) 
to intermolecular [4+2] cycloaddition of the ene-imine system, thus removal of the alkene group in favour of acetylene was investigated. Compound 5d was chemically stable in buffer but with a high level of reactivity towards glutathione. Substitution at the reactive centre gave methyl acetylene 5e which gratifyingly demonstrated an acceptable stability and reactivity profile, with an increase in reactivity of $\sim 15$ fold towards glutathione in comparison to corresponding alkyne amide $4 \mathbf{e}$.

Table 2. Half-life of 4a-e and 5a-e in the presence of glutathione (GSH) and pH7.4 buffer solution alongside calculated LUMO energies.

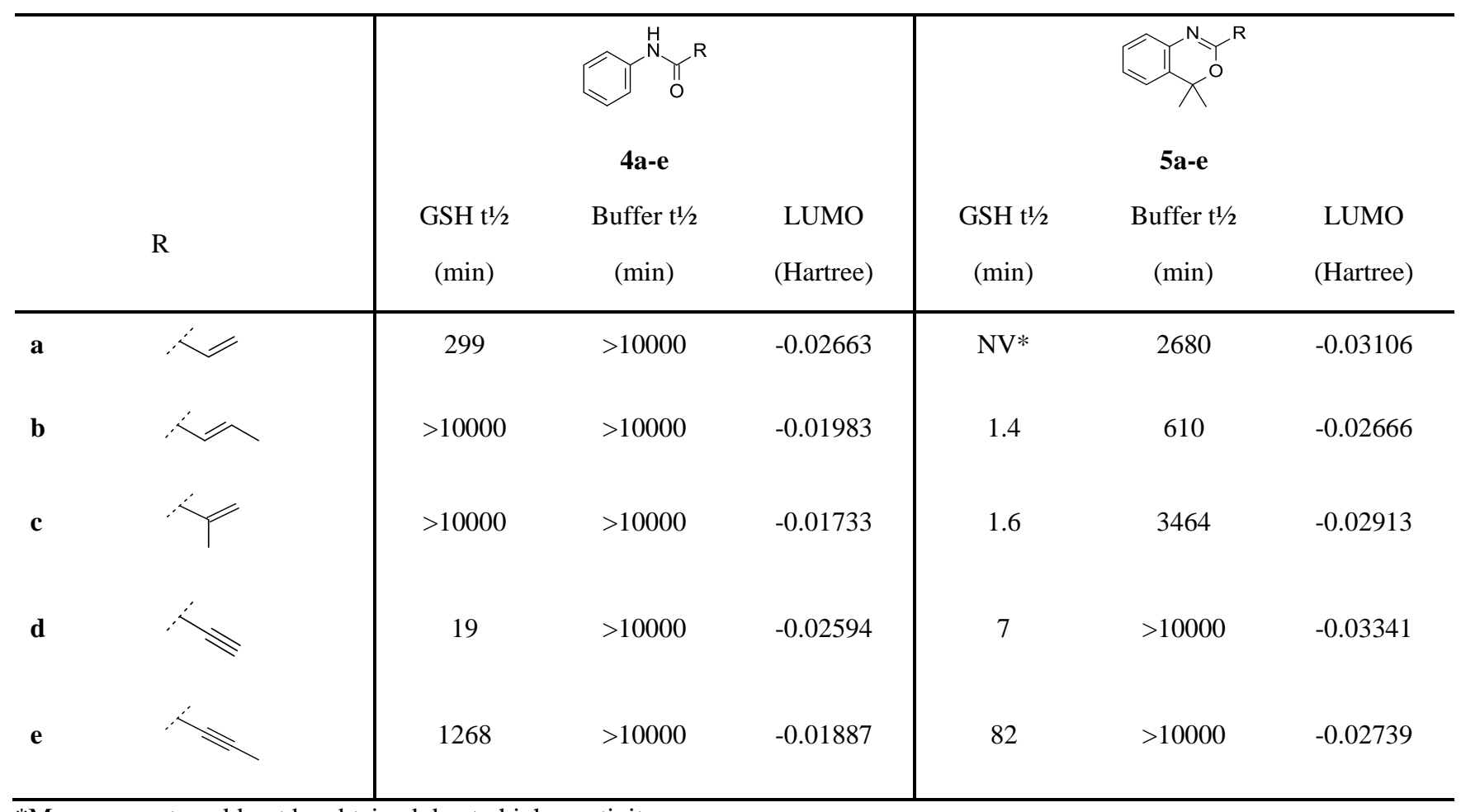

*Measurement could not be obtained due to high reactivity.

a

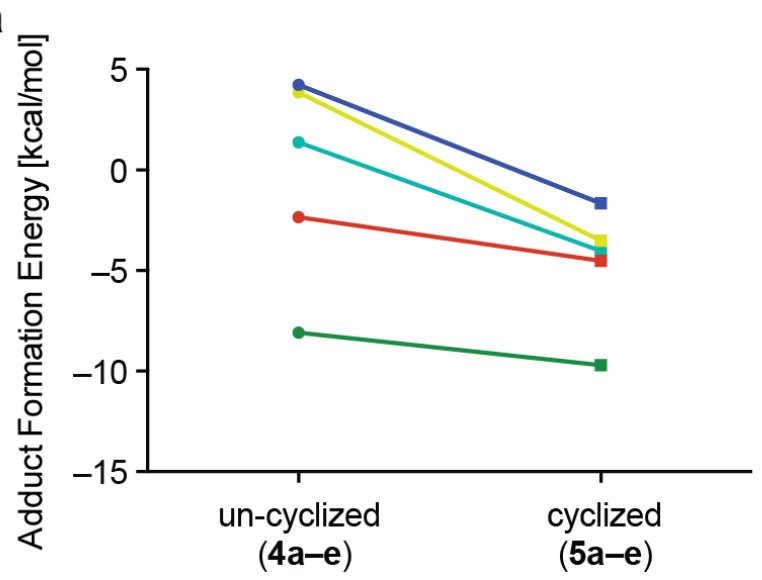

b

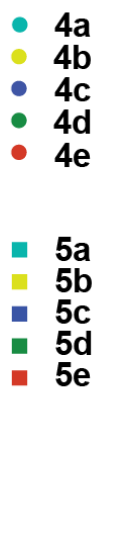

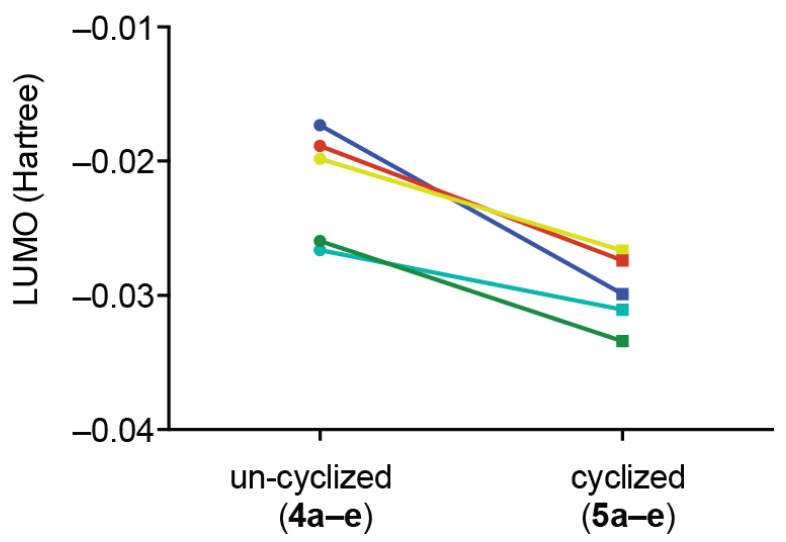

Figure 2. Comparative LUMO and adduct formation energies between cyclized (4a-e) and uncyclized (5a-e) warheads.

The increase in reactivity observed when going from the amides 4a-e to cyclized benzoxazines 5a-e can be partially explained by differences in electronic factors. Incorporation of the benzoxazine moiety extends the conjugation of the Michael acceptor with the 
aromatic ring, and this increase in electrophilicity is reflected in calculated LUMO energies, with a lowering of the LUMO observed in all cases when cyclization occurs (Figure 2). Conjugation of the Michael acceptor orbitals to the aromatic ring also holds the acceptor in a more planar conformation allowing for easier orbital overlap. Adduct formation energy $\left(\Delta E_{R}\right)$ was calculated (compounds 4a-14) following previous literature observations that $\Delta \mathrm{E}_{\mathrm{R}}$ displayed a stronger correlation with $\log \left[\mathrm{GSH} \mathrm{t}_{1 / 2}\right]$ than the transition state energy barrier $\left(\Delta \mathrm{E}^{\ddagger}\right),{ }^{28}$ albeit $\Delta \mathrm{E}^{\ddagger}$ was calculated for a small subset of compounds to confirm the relationship with $\Delta \mathrm{E}_{\mathrm{R}}$ (Table S1). Overall, the correlation between $\log \left[\mathrm{GSH}_{\left.\mathrm{t}_{1 / 2}\right]}\right]$ and LUMO was poor $\left(\mathrm{R}^{2}=0.064\right.$, Figure S5) with little improvement for $\Delta \mathrm{E}_{\mathrm{R}}\left(\mathrm{R}^{2}=0.2\right.$, figure S6). Possible reasons for this weak relationship could be the variety of different compounds as defined by warhead and bicycle size. Even within defined subsets the electronics of warheads can change significantly. The correlation between $\log \left[\mathrm{GSH} \mathrm{t}_{1 / 2}\right]$ and $\Delta \mathrm{E}^{\ddagger}$ showed a vast improvement $\left(\mathrm{R}^{2}=0.73\right.$, Figure $\left.\mathrm{S} 7\right)$ using more defined subsets, however, this could be heavily influenced by subset bias. It is interesting to note that the relationship between $\Delta \mathrm{E}^{\ddagger}$ and $\Delta \mathrm{E}_{\mathrm{R}}$ is not linear as expected but instead dependent upon warhead valence showing strong correlation within these groups $\left(\mathrm{R}^{2}=0.9 \& \mathrm{R}^{2}=0.98\right.$ Figure $\left.\mathrm{S} 8\right)$. Based on this observation, when correlation between $\log \left[\mathrm{GSH} \mathrm{t}_{1 / 2}\right]$ and $\Delta \mathrm{E}_{\mathrm{R}}$ is split similarly based on warhead valence it can be seen that acrylamides within this set show a strong correlation $\left(\mathrm{R}^{2}=0.71\right)$ and acetylenes a weak correlation $\left(\mathrm{R}^{2}=0.03\right)($ Figure $\mathrm{S} 8)$, suggesting that prediction of acetylene based warheads across chemotypes is non-trivial. ${ }^{29,30}$ Recent literature has similarly demonstrated that these approaches also fail for the reactivity prediction of drug-like compounds. ${ }^{31} \mathrm{With}$ electronics being a large contributing factor to the reactivity of the cyclic systems, substitution of the heterocyclic warhead with varying functional groups around the aromatic ring was explored (Table 3). In all cases reactivity towards glutathione was within two-fold of the parent compound 5e and compounds were found to be stable in buffer solution. Despite only small changes, the observed differences in reactivity largely correlated with expected redistribution of electron density around the ring as predicted by LUMO calculations (Figure S9).

Table 3. Half-life in minutes of bicyclic systems bearing functional groups on the aromatic ring with glutathione (GSH)

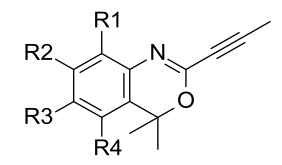

\begin{tabular}{ccccc}
\hline & R1 & R2 & R3 & R4 \\
\hline OMe & 74 & 78 & 133 & 77 \\
$\mathrm{H}$ & 82 & 82 & 82 & 82 \\
$\mathrm{Br}$ & 155 & 105 & 125 & 147 \\
$\mathrm{CO}_{2} \mathrm{Me}$ & - & 134 & 58 & 109 \\
\hline
\end{tabular}

Effect of Scaffold Hopping on Heterocycle Reactivity. Having identified compound 5e as a novel electrophile and explored the effect of electronic changes around the ring, further structural changes to the scaffold were explored (Table 4). Ring expansion to the 7-membered ring system gave compound $\mathbf{6}$ with promising stability and reactivity. This analogue was found to have a decreased level of reactivity relative to the parent 5e. This is most likely due to less efficient orbital overlap between the benzoxazine and aromatic ring in the 7-versus 6-membered ring system. Interestingly, the 7-membered isomer 7 was found to be unstable in buffer; this was most likely because of $\beta$ elimination to give the ring opened alkene and amide functionalities. Ring-contraction to the 5-membered aromatic heterocycle $\mathbf{8}$ also resulted in a large decrease in reactivity along with some inherent instability. Isomeric forms of $\mathbf{5 e}$ were also explored. Switching the oxygen and carbon centres (9) resulted in an increase in reactivity as expected from the removal of the mesomeric electron donor. Compound 10, in which the heteroatoms are swapped relative to 5e was prone to hydrolysis at the imine 
centre, whilst exchange of oxygen for a nitrogen in dihydroquinazoline $\mathbf{1 1}$ gave a compound with very high reactivity towards glutathione but which was intriguingly completely stable in buffer. Compound 11 was shown to have a measured $\mathrm{pK}_{\mathrm{a}}$ of 8.05 compared to 2.69 for the oxygen heterocycle 5e. It is plausible that the observed increase in reactivity is mediated by intermolecular deprotonation of the reactive thiol by this warhead and it has previously been proposed that acrylamides bearing $N, N$ dimethylmethanamine at the $\beta$-position have a higher reactivity towards glutathione as a result of intramolecular base catalysis. ${ }^{14,32}$ Although likely unsuitable for incorporation into drug-like molecules, the high reactivity and stability of $\mathbf{1 1}$ suggested utility in protein labelling studies. Removal or substitution of the geminal dimethyl with a carbonyl gave compounds 12 and 13 which were unsurprisingly inherently unstable. It was found that larger spirocyclic groups could be incorporated and tolerated at this position 14, and that the basic centre here has no impact on reactivity of the electrophile. Comparatively, inclusion of a basic dimethylamino group at the terminus of the Michael acceptor motif 15 results in a >50-fold increase in reactivity towards glutathione, relative to the parent 5e. A much greater rate acceleration was observed for its incorporation into this benzoxazine scaffold than has previously been reported in similarly substituted acrylamide and ynamide Michael acceptors. ${ }^{14,32,33}$

Table 4. Half-life in minutes of warhead isomers in the presence of glutathione (GSH) and pH7.4 buffer.

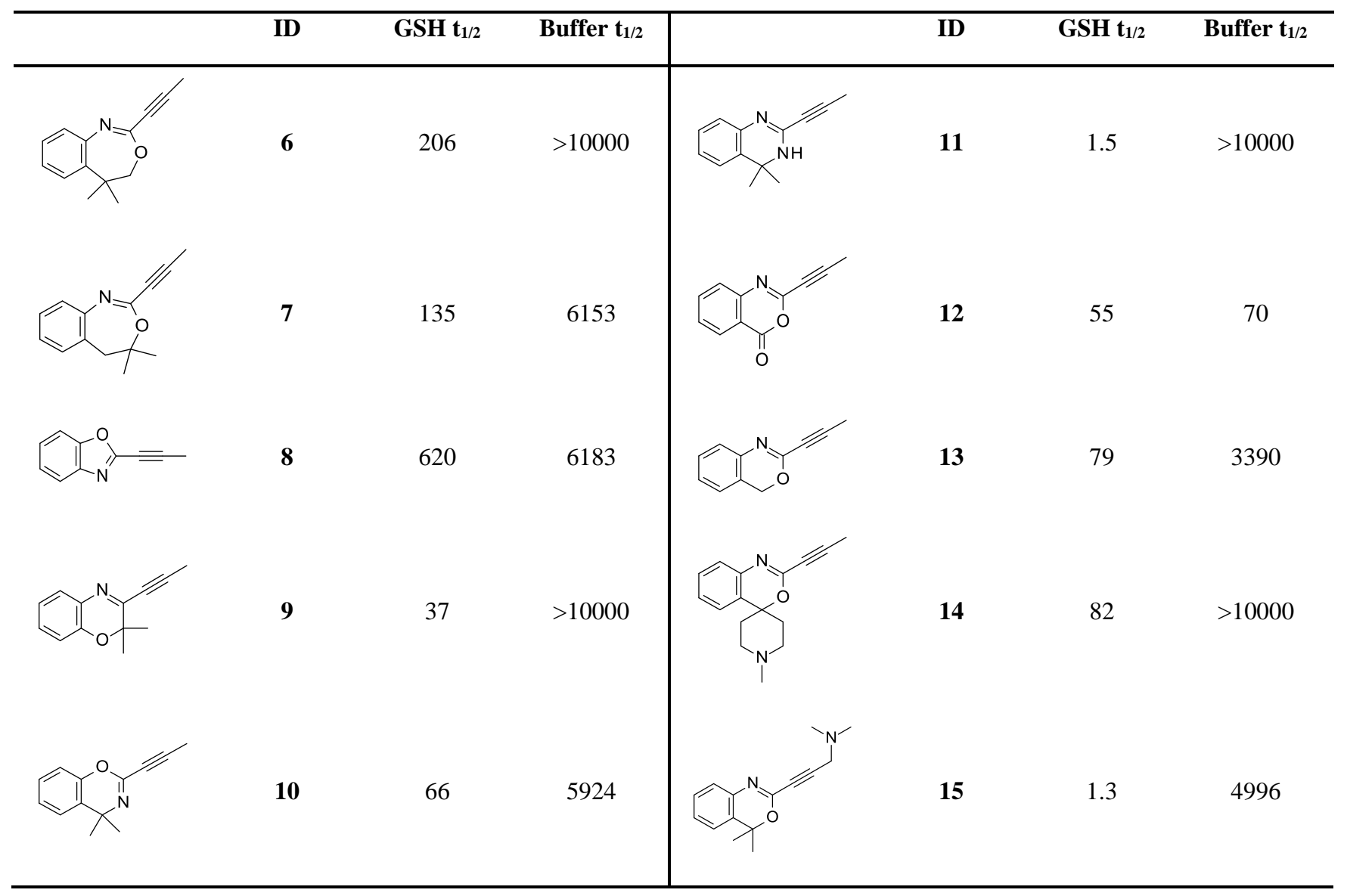

Warhead Selectivity. To ensure the two main warheads of interest $\mathbf{5 e}$ and $\mathbf{1 1}$ were selective for cysteine over other nucleophilic amino acids, kinetic experiments were conducted in both d6-DMSO and pH8 buffer and monitored by ${ }^{1} \mathrm{H}$ NMR and LCMS respectively (Figure 3). NMR experiments were conducted according to a procedure published by Golding et al. ${ }^{34}$ whilst LCMS experiments were designed to mimic GSH assay data at a slightly higher $\mathrm{pH}$. No reaction was observed for either compound with lysine or serine, but complete reaction of the warheads with cysteine occurred. As expected, the dihydroquinazoline analogue $\mathbf{1 1}$ showed a much faster reaction rate than its oxygen counterpart 5e, with complete reaction having occurred before initial spectral data 
could be obtained; thus, an accurate half-life could not be determined in either solvent. Half-lives of 5e with cysteine were calculated by following the disappearance of starting material over time. A mixture of $E$ - and $Z$-isomeric products were also observed for both warheads along with peaks pertaining to bis-addition products after a longer period of incubation.

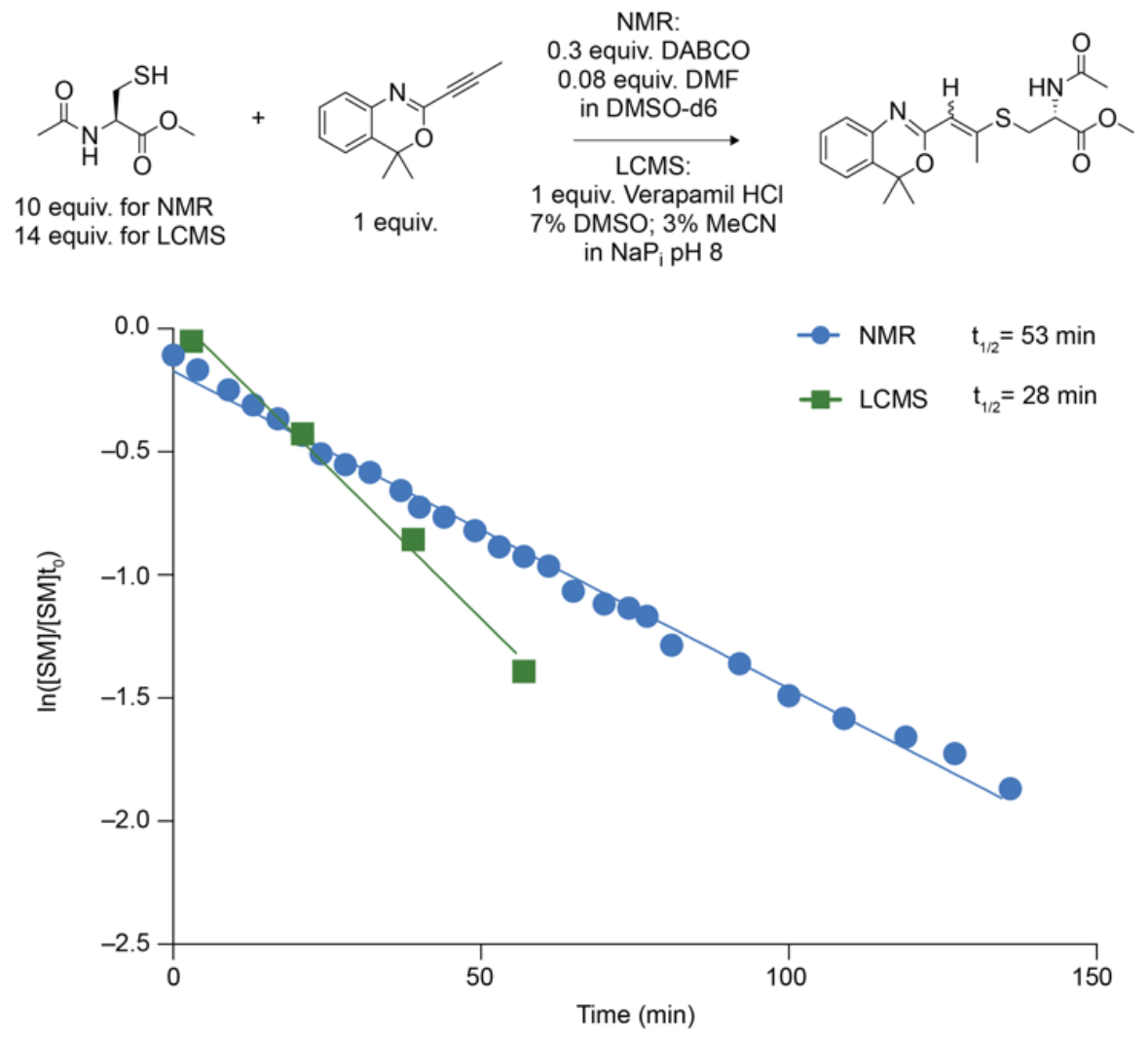

Figure 3. Half-life data for reaction of 5e with 'capped' cysteine. NMR data for 5e in d6-DMSO containing DABCO (0.3 eq.) and DMF as internal standard. LCMS data for $\mathbf{5 e}$ in pH8 phosphate buffer containing verapamil as internal standard.

Protein Labelling Studies. Having demonstrated the selective nature of warheads 5e and $\mathbf{1 1}$ towards cysteine over other amino acids in analytical assays, we decided to test the reactivity towards cysteine-containing protein $\mathrm{C} 2 \mathrm{Am}$ (an engineered variant of the $\mathrm{C} 2 \mathrm{~A}$ domain of Synaptotagmin-I). In both cases, conversion of protein to the corresponding conjugate occurred within 3.5 hours (Figure 4). Interestingly, only 10 equivalents of dihydroquinazoline analogue $\mathbf{1 1}$ were required to affect this reaction. Selectivity for cysteine was determined after trypsin digest and subsequent peptide mapping using mass spectrometry. This data corroborates our previously observed reactivity with native amino acids, demonstrating the bicyclic warheads are highly selective for cysteine. Notably, both conjugates were also found to be stable in human plasma (10\%) solutions over the course of a week (Figures S21-S24). However, when exposed to solutions of $1 \mathrm{mM} \mathrm{GSH}$, the conjugates show significant GSH substitution, indicating cleavage of $\mathbf{5 e}$ or $\mathbf{1 1}$ from the protein (Figures S17-S20). While the mechanism of such displacement is not in the scope of this project, further studies may reveal if such characteristics could lend themselves to a drug delivery platform, wherein the payload could be released upon interacting with cellular GSH levels. We also explored reaction of $\mathbf{5 e}$ and $\mathbf{1 1}$ with the HER2 nanobody 2Rb17c. 2Rb17c displays a reactive, engineered cysteine at the C-terminus of a flexible side chain, making it an ideal target for bioconjugation. ${ }^{35}$ Again, as expected, dihydroquinazoline analogue 11 showed a much higher level of reactivity than the benzoxazine 5e (Figure 5). Complete conversion to the conjugate was observed for 11 in 3 hours with 50 equivalents, whilst $\mathbf{5 e}$ showed only partial conversion using 1000 equivalents within the same period. Extended reaction time led to the formation of dimer, due to depletion of TCEP in phosphate buffer. Although this transformation required the utilization of a greater number of equivalents of $\mathbf{1 1}$, the result was found to be comparable to labelling of the same nanobody with a carbonylacrylic reagent. ${ }^{36}$ Although likely too reactive to be incorporated into a drug, these data suggest 
the dihydroquinazoline analogue $\mathbf{1 1}$ holds potential as a fragment probe for site-selective cysteine protein modification which requires quick and effective reaction. Often maleimides are used for this purpose due to their high levels of reactivity; however, the products and maleimides themselves are often unstable and prone to retro-Michael addition and hydrolysis. ${ }^{23,37}$ Indeed, when we compare simple maleimides with similar reactivity levels to our dihydroquinazoline warhead there are large differences in buffer stability. For example, $N$-(p-tolyl)maleimide has a measured half-life of 57 minutes in pH7.4 buffer, compared to >10000 minutes for dihydroquinazoline 11. Moreover, maleimides often show some lysine reactivity at slightly basic $\mathrm{pH}$, differentiating our new warhead further. ${ }^{25}$ 
a

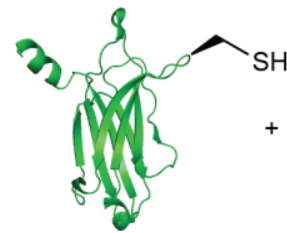

C2Am-Cys 95

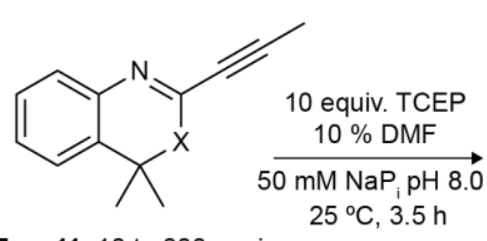

5 or 11,10 to 300 equiv.

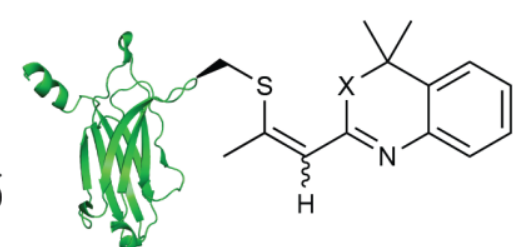

C 100

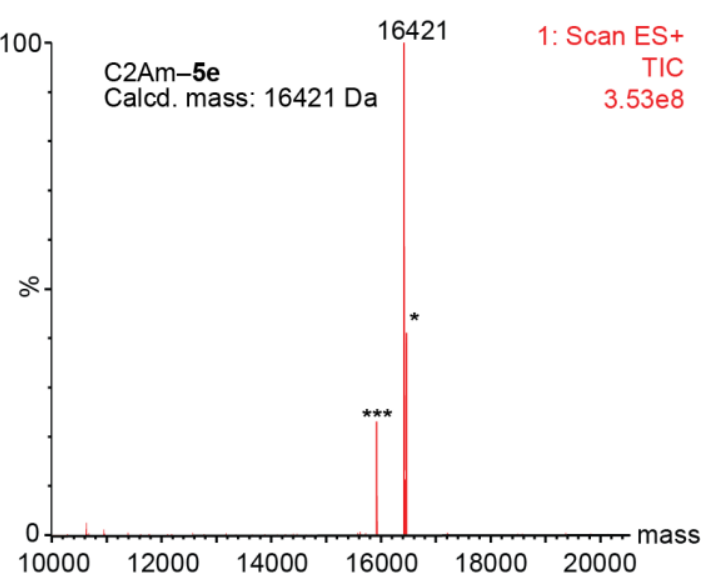

d

b 100

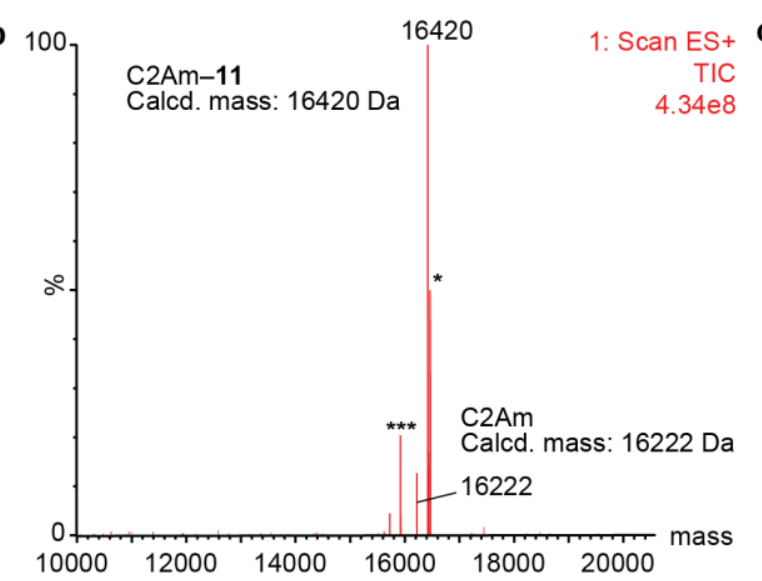

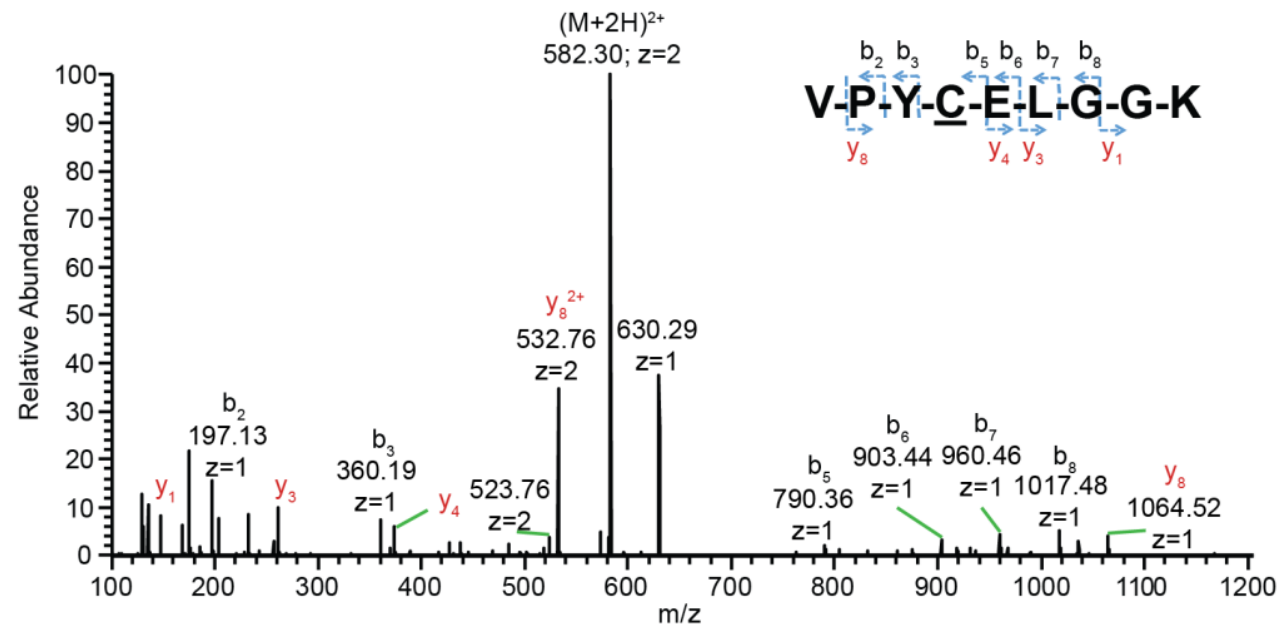

e

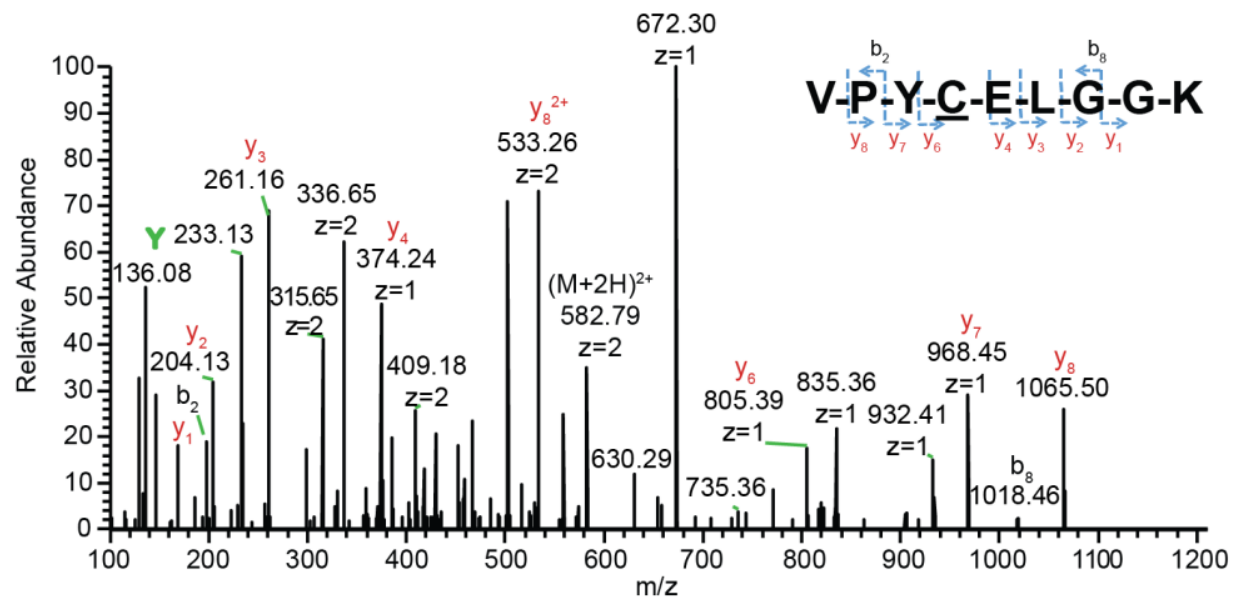

Figure 4. a) Schematic of the reaction of C2Am with bicyclic warheads 5e and $\mathbf{1 1}$ b) Deconvoluted LCMS mass spectrum for the C2Am-11 conjugate (Product: $16420 \mathrm{~m} / z ;[\mathrm{M}+198]^{+}$) c) Deconvoluted LCMS mass spectrum for the C2Am-5e conjugate (Product: $\left.16421 \mathrm{~m} / \mathrm{z} ;[\mathrm{M}+199]^{+}\right)$d) MS/MS spectrum of the $582.30 \mathrm{~m} / \mathrm{z}$ doubly charged ion of the tryptic peptide VPYCELGGK, modification 
at the Cys residue of C2Am-11 e) MS/MS spectrum of the $582.79 \mathrm{~m} / \mathrm{z}$ doubly charged ion of the tryptic peptide VPYCELGGK, modification at the Cys residue of C2Am-5e.

a

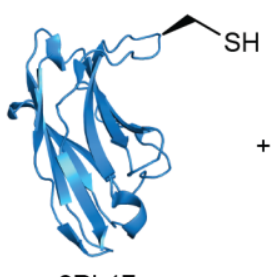

$2 \mathrm{Rb} 17 \mathrm{c}$

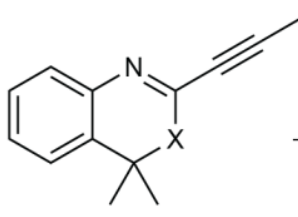

5e or 11,50 to 1000 equiv.

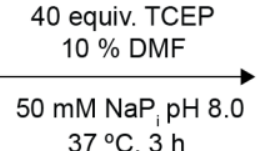

$37^{\circ} \mathrm{C}, 3 \mathrm{~h}$

b

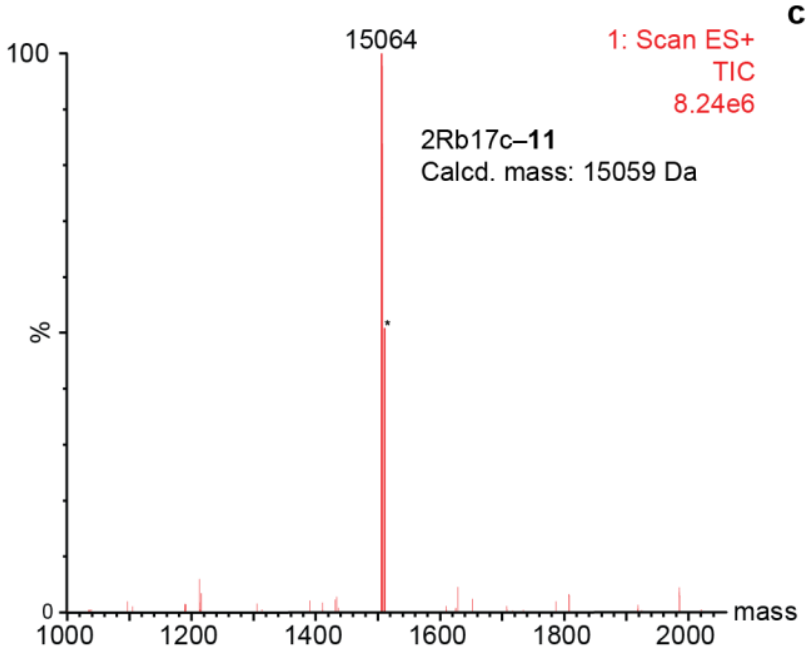

C

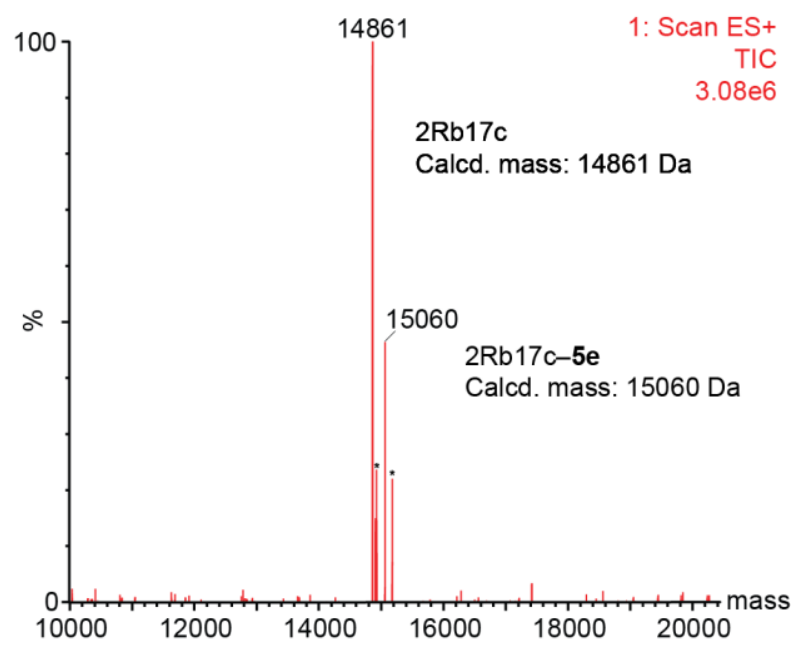

Figure 5. a) Schematic of the reaction of 2Rb17c with bicyclic warheads $\mathbf{5 e}$ and $\mathbf{1 1}$ b) Deconvoluted LCMS mass spectrum for the 2Rb17c-11 conjugate (Product: $15064 \mathrm{~m} / \mathrm{z} ;[\mathrm{M}+198]^{+}$, calc.d 15059) c) deconvoluted LCMS mass spectrum for the C2Am-5e conjugate (Product: $15060 \mathrm{~m} / \mathrm{z} ;[\mathrm{M}+199]^{+}$, calc.d 15060)

Utilization of Warheads in Kinase Drug Scaffolds. To explore application of these heterocyclic systems in a drug-like setting, we proposed to incorporate benzoxazine $\mathbf{5 e}$ into a kinase inhibitor which was already known to bind to a cysteine residue. Scaffolds $\mathbf{5 e}$, 6 and $\mathbf{9}$ all represent potentially useful warheads to explore, showing high buffer stability and acceptable GSH reactivity - we prioritized 5e due to its intermediate reactivity, ease of synthesis and lower size and lipophilicity relative to 6. EGFR T790M is a well explored kinase mutant with multiple known inhibitors, including osimertinib which binds to C797 in the active site. ${ }^{38}$ We therefore proposed that by paring back the osimertinib scaffold, removing the methoxy group and basic side chain for ease of synthesis, that we could retain some EGFR potency and allow for a comparison between acrylamide 16, methylacetylene amide $\mathbf{1 7}$ and our warhead of interest 18 (Scheme 1). The synthesis of these compounds followed the route described in Scheme 2, from common intermediate 19, which has previously been described for the synthesis of osimertinib. ${ }^{38}$ The synthesis of all three compounds began with an $\mathrm{SN}_{\mathrm{Ar}}$ reaction followed by reduction of the nitro group to furnish an aniline intermediate (21 or $\mathbf{2 2}$ ). Treatment of $\mathbf{2 1}$ with acryloyl chloride or 2-butynoic acid and DCC gave the desired reference compounds $\mathbf{1 6}$ and $\mathbf{1 7}$. Addition of methyl Grignard to 22 afforded a tertiary alcohol intermediate $\mathbf{2 3}$, which subsequently underwent amide coupling with 2-butynoic acid, followed by dehydrative cyclization under acidic conditions to give target compound $\mathbf{1 8}$ in just 5 steps and 24\% overall yield from intermediate 19.

Scheme 1. Scaffold modifications leading to compound 18 


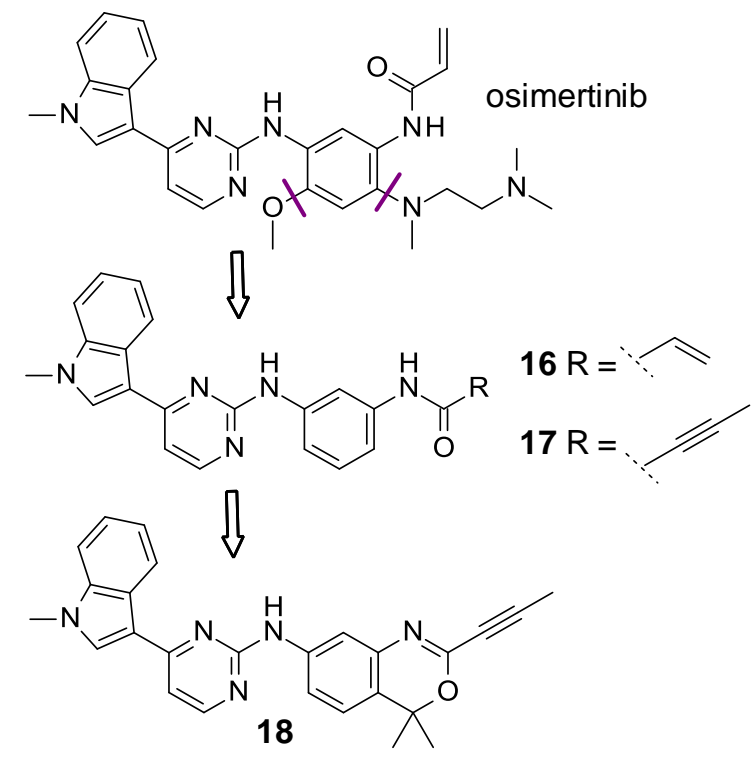

Upon biochemical testing we saw a large drop off in potency against EGFR T790M for 18, in comparison to the reference compounds 16 and 17. However, upon testing against a wider kinase panel at ThermoFisher it was found that $\mathbf{1 8}$ was instead highly potent against Janus kinase 3 (JAK3) with an $\mathrm{IC}_{50}$ of $0.06 \mu \mathrm{M}$. Although $\mathrm{K}_{\mathrm{i}}$ and $\mathrm{K}_{\text {inact }}$ data would ideally be derived, $\mathrm{IC}_{50}$ values can be used to make useful inferences about the potency of compounds provided they have consistent assay timescales and the reactivities have been quantified and shown to be in a similar range, as is the case for these studies. JAK3 forms part of the Janus kinase family, which also includes JAK1, JAK2 and TYK2. These kinases work together to drive signalling in both type I and II cytokine receptors. ${ }^{39}$ Moreover, 18 had a much more selective profile across the panel than either of the reference compounds, inhibiting only 7 kinases $>60 \%$ (Figure 6). In particular, 18 shows much greater selectivity over other kinases containing a known reactive cysteine in the same active site position, as well as against the JAK1 and JAK2 isoforms (Table 5). Unlike JAK3, JAK1 and JAK2 do not contain a reactive cysteine in the active site $^{40}$ and so the observed selectivity strongly suggested a covalent mode of action.

Scheme 2. Synthesis of kinase drug analogues 16,17 and 18

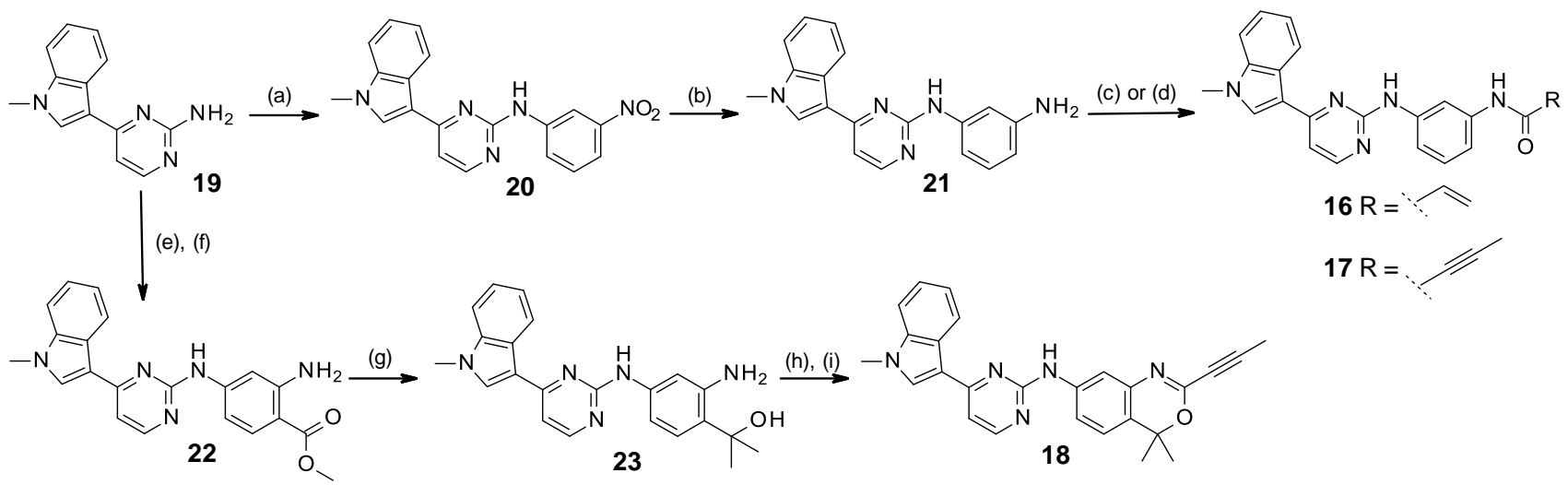

Reaction conditions: (a) $m$-nitroaniline, pTSA, EtOH, $150^{\circ} \mathrm{C}, \mathrm{MW}$; (b) $\mathrm{NH}_{4} \mathrm{Cl}, \mathrm{Fe}, \mathrm{EtOH} / \mathrm{H}_{2} \mathrm{O}, 80^{\circ} \mathrm{C}, 68 \%$ (2 steps); (c) acryloyl chloride, Et 3 N, DCM, 19\% of 16; (d) 2-butynoic acid, DCC, DCM, 54\% of 17; (e) ethyl 4-amino-2-nitrobenzoate, $p$ TSA, EtOH, $150^{\circ} \mathrm{C}, \mathrm{MW}$; (f) $\mathrm{NH}_{4} \mathrm{Cl}, \mathrm{Fe}, \mathrm{EtOH} / \mathrm{H}_{2} \mathrm{O}, 80^{\circ} \mathrm{C}, 62 \%$ (2 steps); (g) MeMgBr, THF; (h) 2-butynoic acid, DCC, DCM; (i) MsOH, DCM, $45^{\circ} \mathrm{C}, 38 \%$ (3 steps). 
Table 5. Enzyme $\mathrm{IC}_{50}$ data for selected cysteine containing kinases and JAK family members.

\begin{tabular}{cccc}
\hline & $\mathbf{1 6}$ & $\mathbf{1 7}$ & $\mathbf{1 8}$ \\
\hline JAK3 & 0.01 & 0.39 & 0.06 \\
JAK2 & 0.14 & 0.23 & 3.11 \\
JAK1 & 1.01 & 1.98 & $>10$ \\
EGFR T790M & 0.18 & 0.22 & 2.80 \\
BMX & 0.13 & 1.05 & 0.67 \\
BLK & 0.57 & 4.76 & $>10$ \\
BTK & 0.28 & 3.32 & 1.77 \\
\hline
\end{tabular}

$\mathrm{IC}_{50}$ data were obtained at ThermoFisher Scientific.

To probe our hypothesis and confirm that covalent binding to JAK3 was occurring, we tested compounds 16,17 and 18 against the JAK kinases at high ATP concentration $(1 \mathrm{mM})$. As expected, a large drop off in potency was observed for JAK1 and JAK2 whilst potency was retained in JAK3 for both $\mathbf{1 6}$ and 18, consistent with irreversible binding (Table 6). Interestingly, the methylacetylene amide 17 was also subject to a large drop in potency for JAK3 at $1 \mathrm{mM}$ ATP concentration, indicating that this compound may not be binding covalently. Covalent binding of $\mathbf{1 8}$ to JAK3 was confirmed using mass spec analysis (Figure S12). Docking of $\mathbf{1 8}$ within the JAK3 active site, anchoring through the covalent bond to Cys909, suggests that the central aminopyrimidine ring forms hydrogen bonds with Leu905 in the hinge region (Figure 7). The predicted binding mode of $\mathbf{1 8}$ is consistent with a covalent literature compound with a shared hinge binding motif, complexed to JAK3 (PDB 4Z16, supporting information). In order to assess whether 18 maintained selectivity against wider cysteine-containing proteins within a cellular environment, the specificity of both $\mathbf{1 6}$ and $\mathbf{1 8}$ by global cysteine reactivity profiling was examined (Figure 8). NCI-H358 cells were treated with $10 \mu \mathrm{M}$ of compound $\mathbf{1 6}$ or $\mathbf{1 8}$, or vehicle for 2 hours. Any remaining unreacted, solvent exposed cysteine residues were then reacted with iodoacetamide desthiobiotin and proteins subsequently digested with trypsin. The resulting biotinylated peptides were enriched with streptavidin and analyzed by MS to determine which targets each compound was capable of binding to. It should be noted that this lung adenocarcinoma cell line unfortunately does not express JAK3 protein, which we assessed by use of two different JAK3 antibodies. This observation is consistent with literature reports that JAK3 protein was undetectable in this cell line, and that siRNA against JAK3 had no effect on levels of phospho-STAT, a downstream marker, suggesting that JAK3 signalling may not be important in NCI-H358 cells. ${ }^{50}$ Despite this, the assay is a useful assessment of cellular cysteine promiscuity and has recently been used by us to probe the selectivity of a covalent acrylamide based inhibitor of the mutant GTPase KRAS ${ }^{\mathrm{G} 12 \mathrm{C}} .{ }^{51}$ Both compounds were found to be selective across the soluble cysteinome, although acrylamide 16 was found to bind to Cys36 of the RNA polymerase II-associated factor 1 homolog (PAF1) and Cys1101 of Reticulon-4 (RTN4) (supporting information). In contrast these cysteine residues were not impacted in cells treated with compound $\mathbf{1 8}$, and indeed no other proteins were found to significantly bind to benzoxazine $\mathbf{1 8}$, which is noteworthy given the analysis encompassed 3687 different proteins. 


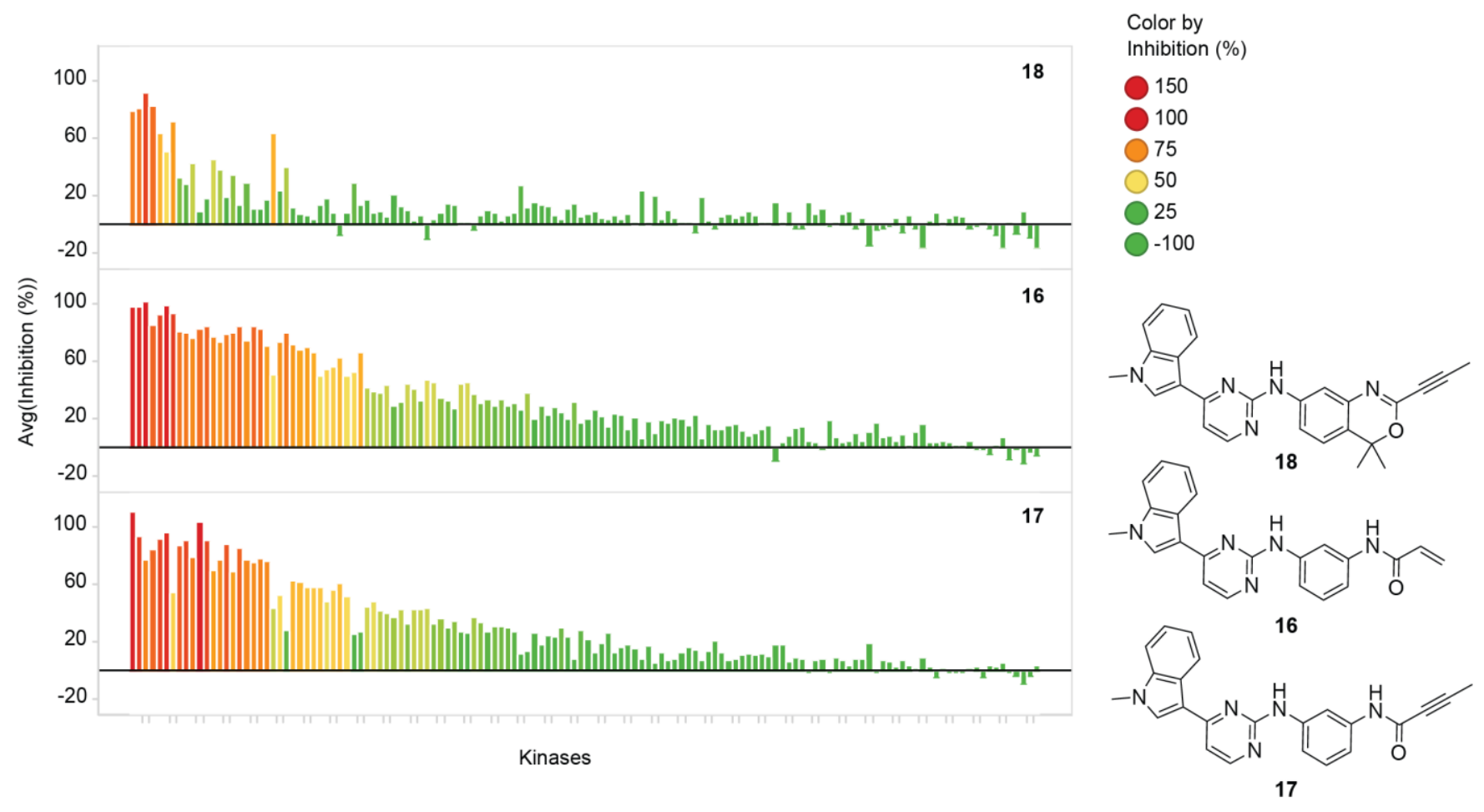

Figure 6. Comparative selectivity of inhibitors 16-18 in a panel of 140 human kinases run in the SelectScreen kinase panel at ThermoFisher Scientific at a single concentration of $1 \mu \mathrm{M}$

Table 6. $\mathrm{IC}_{50}$ data at varying ATP concentration for JAK family members compared with literature $\mathrm{K}_{\mathrm{m}}{ }^{41}$

\begin{tabular}{cccccc}
\hline Kinase & {$[\mathbf{A T P}] \boldsymbol{\mu M}$} & $\mathbf{1 8}$ & $\mathbf{1 6}$ & $\mathbf{1 7}$ & $\mathbf{K m ~ A T P}(\boldsymbol{\mu M})$ \\
\hline \multirow{2}{*}{ JAK3 } & 10 & 0.06 & 0.01 & 0.23 & 2.9 \\
& 1000 & 0.09 & 0.02 & 6.43 & 8.5 \\
\hline \multirow{2}{*}{ JAK2 } & 25 & 3.11 & 0.14 & 0.23 & 31.8 \\
& 1000 & $>10$ & 3.19 & 6.74 & 1.98 \\
\hline \multirow{2}{*}{ JAK1 } & 75 & $>10$ & 1.01 & $>10$ & \multirow{2}{*}{0.43} \\
\hline
\end{tabular}

$\mathrm{IC}_{50}$ data were obtained at ThermoFisher Scientific.

As well as having an improved selectivity profile across the kinome, compound $\mathbf{1 8}$ containing the novel warhead also showed improved in vitro pharmacokinetic properties, making it arguably superior to its acrylamide counterpart (Table 7). Clearance in human liver microsomes and both human and rat hepatocytes were drastically improved, with a $\sim 9$-fold difference in microsomal clearance observed between 16 and 18. Improvements in hERG $\mathrm{IC}_{50}$ were also observed. Interestingly, addition of the lipophilic geminal dimethyl group is also $\log \mathrm{D}$ neutral across the scaffolds. Despite the improvements brought about from our novel warhead, all compounds unsurprisingly suffered from high plasma protein binding and low solubility due to their high lipophilicity. It is also interesting to note that although reactivity towards glutathione is increased for the new warhead $\mathbf{1 8}$ it is still within an acceptable range for a drug substance and is in a comparable reactivity range to osimertinib (GSH $\mathrm{t}_{1 / 2}=121$ min under this same protocol). 


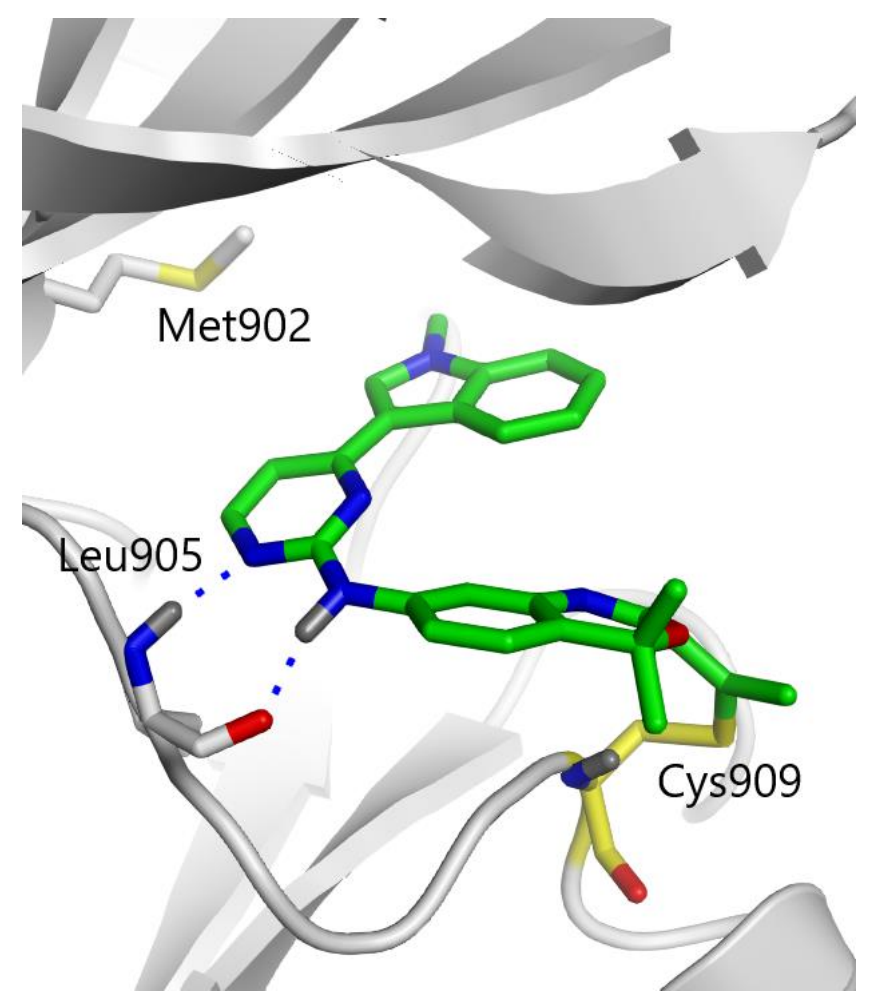

Figure 7. Docking of $\mathbf{1 8}$ bound in JAK3. The aminopyrimidine forms the expected donor-acceptor hinge interaction, with covalent capture of Cys909.
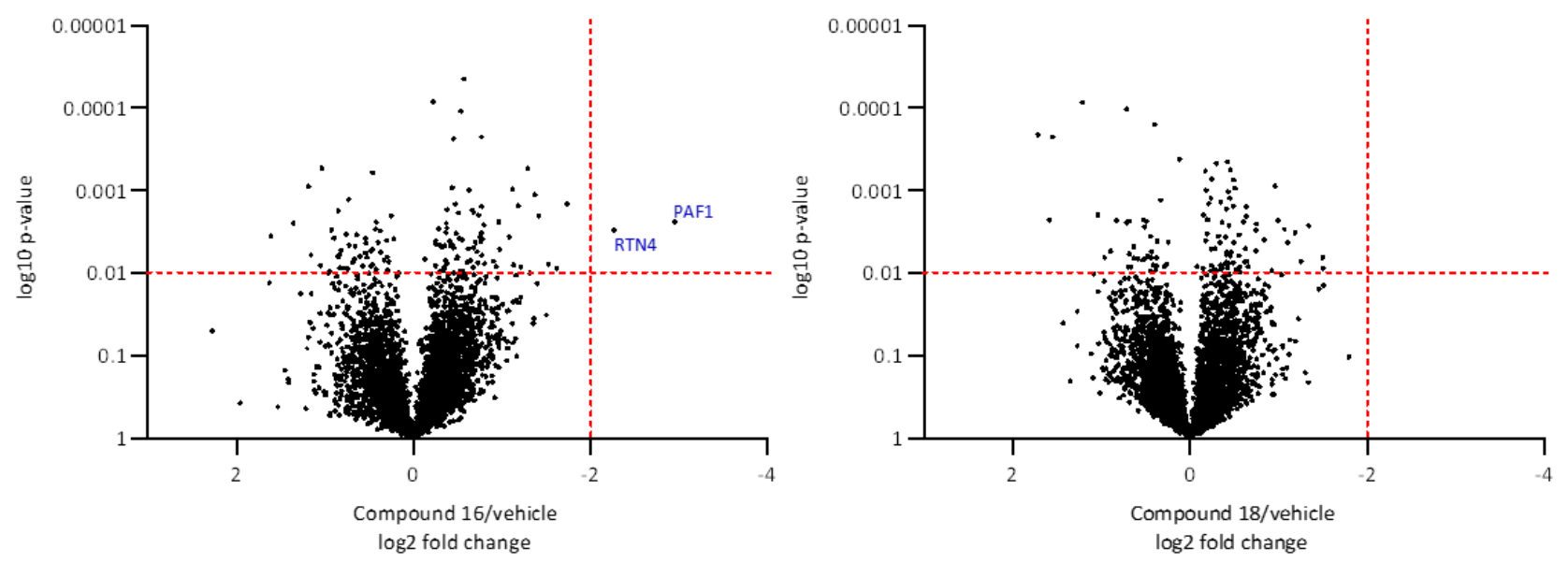

Figure 8. Free cysteine profiling of compound 16 and 18. A $\log 2$ fold change of $>-2$ and a p-value of $<0.01$ from control are indicated in red.

Table 7. Comparison of in vitro pharmacokinetic properties of compounds 16-18

\begin{tabular}{cccc}
\hline & $\mathbf{1 8}$ & $\mathbf{1 6}$ & $\mathbf{1 7}$ \\
\hline GSH t $_{1 / 2}(\min )^{\mathrm{a}}$ & 100 & 310 & 978 \\
hERG IC $_{50}(\mu \mathrm{M})$ & $>40$ & 29 & 18 \\
PPB $(\% \text { free })^{\mathrm{b}}$ & $<0.3$ & 0.1 & $<3.0$
\end{tabular}




\begin{tabular}{|c|c|c|c|}
\hline Rat Heps $(\mu \mathrm{L} / \mathrm{min})^{\mathrm{c}, \mathrm{d}}$ & 74 & 136 & 163 \\
\hline Hu Mics $(\mu \mathrm{L} / \mathrm{min} / \mathrm{mg})^{\mathrm{c}, e}$ & 13 & 103 & 39 \\
\hline Hu Heps $(\mu \mathrm{L} / \mathrm{min})^{c, d}$ & 19 & 43 & 97 \\
\hline $\log \mathrm{D}$ & 4.3 & 4.3 & 4.2 \\
\hline Solubility $(\mu \mathrm{M})^{\mathrm{f}}$ & 0.9 & 3.0 & 0.5 \\
\hline
\end{tabular}

Having established the differentiated pharmacokinetic properties of the benzoxazine warhead against the acrylamide, we sought to explore its use in a system where acrylamide was previously unsuccessful. Part of our original hypothesis was that rigidification of the Michael acceptor system within the heteroaromatic ring would provide a specific vector for attack, holding the drug in a reactive conformation. A previous in-house project had sought to target c-KIT, a receptor tyrosine kinase involved in intracellular signalling, mutated forms of which play a key role in the occurrence of gastrointestinal stromal tumors (GIST) ${ }^{42} \mathrm{c}-\mathrm{KIT}$ and the related KDR kinase, both bear a cysteine in the same active site position (Cys788 in c-KIT and Cys1024 in KDR) and analysis of PDB structures showed that in the majority of cases the cysteine in c-KIT pointed into the active site (towards the ligand); whilst in KDR, the cysteine was found to point away from the pocket in $c a .80 \%$ of the structures analysed (Figure S2). There are two basic residues adjacent to the cysteine in KDR, which have the potential to modulate the $\mathrm{pK}_{\mathrm{a}}$ of Cys1024 and cause the thiol to face away from the pocket. In c-KIT there is instead an asparagine residue (Asn787) which would be unable to modulate the orientation of the cysteine to the same extent. The C-helices of the two kinases also have different residues at their termini, altering the size and shape of the pockets; with resultant variation in the affinity of ligands ${ }^{43}$ Compound $\mathbf{2 4}$ was a compound originally synthesized in an in-house project to target the kinase PDGFR, shown to have affinity for c-KIT and whose binding mode was later solved in both c-KIT and KDR crystal structures. ${ }^{44}$ From these it was evident that the basic side chain pointed towards Cys788 in c-KIT and thus could act as a handle for addition of a cysteine reactive warhead. These presumptions led to the synthesis of acrylamide $\mathbf{2 5}$ which was designed to place the Michael acceptor in position for covalent reaction with the thiol (Table 8). In the event, addition of the Michael acceptor to the scaffold was not found to substantially improve potency towards c-KIT, although it did reduce potency towards KDR by $c a$. 10-fold. Upon solving the X-ray crystal structure of $\mathbf{2 5}$ bound to c-KIT it became apparent that the compound was binding reversibly (Figure $\mathrm{S} 1$ and $8 \mathrm{C}$ ). The flexible acrylamide was found to 'bend backwards' in the active site, away from Cys 788, to form interactions with the water network. Rowley and Williams recently reported calculated $\mathrm{pK}_{\mathrm{a}}$ 's for a number of druggable cysteines in selected protein kinases, which included c-KIT Cys788 in both the DFG-in and DFG-out conformations. ${ }^{45}$ In both cases, the thiol $\mathrm{pK}_{\mathrm{a}}$ was computed to be $>21$, suggesting a significant barrier to deprotonation for formation of the reactive anionic thiolate and, thus, a more reactive warhead may be required for covalent bond formation.

Table 8. Enzyme $\left(\mathrm{IC}_{50}\right)$ and cell $\left(\mathrm{GI}_{50}\right)$ potency data in a series of KIT / PDGFR inhibitors. Data is the mean of at least two determinations. 
<smiles>[R]NC(=O)Cc1ncc(Oc2ccnc3cc(OC)ccc23)cc1OC</smiles>

\begin{tabular}{|c|c|c|c|c|c|}
\hline Format & Kinase & {$[\mathbf{A T P}] \mu \mathbf{M}$} & 24 & 25 & 26 \\
\hline \multirow{11}{*}{ Enzyme } & c-KIT & 300 & 0.581 & 0.240 & 2.08 \\
\hline & KDR & 75 & 0.050 & 0.403 & 0.538 \\
\hline & KDR & 1000 & - & 1.380 & $>9.71$ \\
\hline & $\operatorname{PDGFR} \alpha$ & 10 & - & 0.004 & 0.022 \\
\hline & PDGFR $\alpha$ & 100 & - & 0.003 & 0.031 \\
\hline & PDGFR $\alpha$ & 1000 & - & - & 0.107 \\
\hline & PDGFR $\beta$ & 100 & - & 0.008 & 0.033 \\
\hline & PDGFR $\beta$ & 1000 & - & - & 0.113 \\
\hline & PDGFR $\alpha$ V561D & 50 & - & 0.001 & 0.004 \\
\hline & PDGFR $\alpha$ V561D & 100 & - & 0.001 & 0.004 \\
\hline & PDGFR $\alpha$ V561D & 1000 & - & - & 0.005 \\
\hline \multirow{4}{*}{ Cell } & Ba/F3 KIT Exon9 Insertion & - & 0.021 & 0.006 & 0.067 \\
\hline & $\mathrm{Ba} / \mathrm{F} 3$ Tel- PDGFR $\alpha$ & - & 0.002 & 0.001 & 0.011 \\
\hline & $\mathrm{Ba} / \mathrm{F} 3$ Tel- PDGFRb & - & 0.002 & 0.008 & 0.036 \\
\hline & $\mathrm{Ba} / \mathrm{F} 3$ parental & - & $>10$ & 7.241 & $>10$ \\
\hline
\end{tabular}

We hypothesized that the lack of covalent reactivity observed for the acrylamide could be attributed to a combination of the flexibility of the molecule, placing the acrylamide in a hydrophilic area of the binding pocket, and the low nucleophilicity of the targeted cysteine. As our new benzoxazine warheads have a rigid conformation we proposed that covalent binding could be achieved in this context, as the molecule would maintain the reaction vector needed within the binding site. Molecular docking therefore led to the proposal that compound $\mathbf{2 6}$ (Table 8) would be optimally orientated to facilitate covalent reaction (supporting information, Figure S13). Upon synthesis, potency data revealed 26 to be 10-fold less active than the acrylamide 25 against c-KIT. However, the same trend in pharmacokinetic properties, switching from the acrylamide $\mathbf{2 5}$ to the benzoxazine $\mathbf{2 6}$, was observed for the c-KIT analogues as had previously been seen in the JAK3 series (Table S1). Again, it is interesting to note that despite a 2-fold increase in glutathione reactivity relative to $\mathbf{2 5}$, that clearance in human liver microsomes and rat hepatocytes were improved, whilst minimal change in $\log \mathrm{D}$ was observed. 
Inhibitor 25 and 26 retain potent PDGFR activity and the potency of new warhead $\mathbf{2 6}$ against several PDGFR isoforms at varying concentrations of ATP is, as in the JAK example before, strongly suggestive of a covalent mode of action in this kinase. For technical reasons, we were unable to run the c-KIT assay across similar ATP concentration ranges. However, we were able to obtain an X-ray crystal structure of $\mathbf{2 6}$ in both c-KIT and KDR which showed the novel warhead to bind covalently to Cys788 in c-KIT as hypothesized (Figure 9), whilst binding reversibly in KDR. The relatively reactive nature of 26, demonstrated by a glutathione half-life of 65 minutes, may partially explain why covalent binding in c-KIT is observed despite the predicted high pKa of the thiol in Cys788. Although we recognise that the unusually high concentrations of both protein and compound in co-crystallization may drive covalent bond formation that will not be seen in the in vitro activity assay, we believe the combination of PDGFR activity data at varying ATP concentrations and lack of covalent binding in KDR crystal structure support the clear differentiation of this new warhead from a standard acrylamide in the context of this ligand-protein pairing. A similar binding mode was retained switching from the acrylamide 25 to benzoxazine 26 warhead. Acrylamide 25 forms a hydrogen bonding interaction between the amide $\mathrm{NH}$ and Asp810 in the conserved DFG motif as well as an interaction with Pro573 through hydrogen bonding of the carbonyl to the water network. Despite forming a covalent interaction with Cys788, 26 does not form further interactions to the backbone in this region. Interestingly, when bound in KDR the benzoxazine warhead 26 is observed to have flipped $180^{\circ}$ relative to the c-KIT structure, despite similar binding interactions being formed with the quinoline and pyridine rings. This ring flip places the methyl acetylene into a hydrophobic pocket of the enzyme which is not accessed in c-KIT. Covalent selectivity was therefore realised for different reasons than originally hypothesized. 


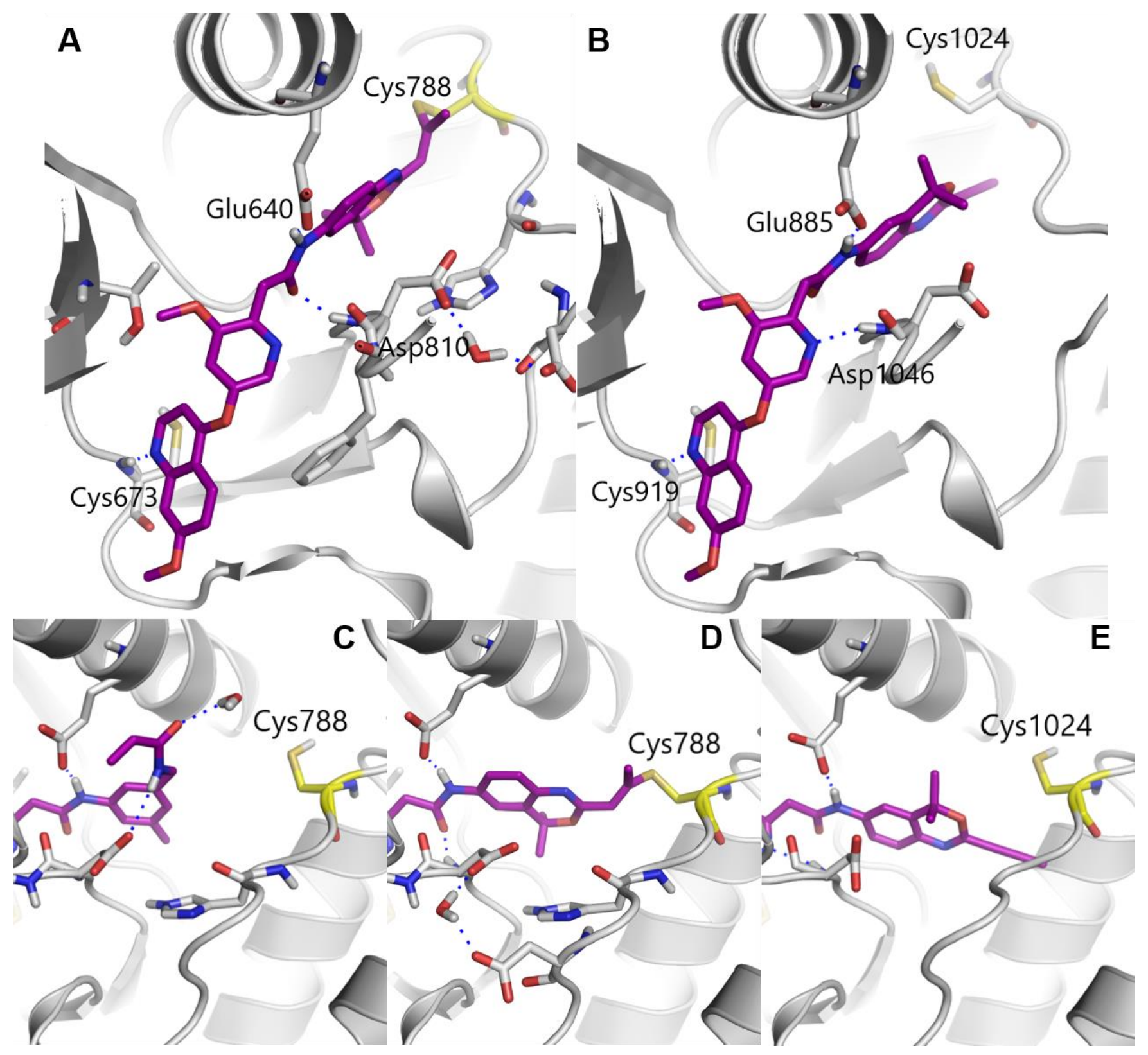

Figure 9. Crystal structures of compound $\mathbf{2 6}$ bound in c-KIT and KDR. A) Crystal structure of 26 covalently bound in c-KIT (6XVB). B) Crystal structure of $\mathbf{2 6}$ bound in KDR (6XVK). C) View of compound 25 warhead bound in c-KIT (6XVA). D) View of compound 26 warhead bound in c-KIT (6XVB). E) View of compound 26 warhead bound in KDR (6XVK).

To our knowledge only one covalent binder of c-KIT (Cys788) has been previously described. Winssinger et al. reported the use of a modified version of the imatinib scaffold bearing a reactive $\alpha$-chloro amide in place of piperazine. ${ }^{46}$ Binding to Cys788 was proven by MS-MS although no crystal structure was solved. Acrylamide versions of the modified scaffold were also tested but not reported to be covalent. Benzoxazine $\mathbf{2 6}$ is therefore the first example of a Michael acceptor system successfully binding to Cys788 and also represents the first crystal structure of c-KIT bearing a covalently modified ligand. To further assess the specificity of the ligand $\mathbf{2 6}$, profiling against a panel of 403 kinases was carried out. There is a high level of homology associated with c-KIT, PDGFR and CSF$1 \mathrm{R}^{47,48}$ and ligands, such as imatinib, are known to inhibit both c-KIT and PDGFR. ${ }^{49}$ More interestingly, PDGFR and c-KIT both contain a cysteine in the same position of the DFG region, and Winssinger et al. were able to demonstrate covalent binding to Cys814 in PDGFR $\alpha$ as well as Cys788 in c-KIT., ${ }^{46}$ Indeed, ligand 26 was found to be highly selective when tested at a single $1 \mu \mathrm{M}$ concentration, inhibiting only 8 kinases at $>60 \%$ inhibition, which included both PDGFR $\alpha$ and PDGFR $\beta$. In order to assess the 
potential of $\mathbf{2 6}$ to inhibit c-KIT and PDGFR in a cellular environment, and in particular to check how the new warhead performed relative to the acrylamide analogue in this context, compounds 24-26 were tested in a panel of Ba/F3 cell lines transfected with PDGFR $\alpha$, PDGFR $\beta$ and an Exon9 insertion mutant of c-KIT (Table 8). Proliferation of these cell lines is dependent upon the introduced construct for growth, and to monitor for non-specific effects on viability in these cells, a parental Ba/F3 line (no introduced construct) is run in parallel. Engineered cell lines including Ba/F3 have been shown previously to faithfully mimic clinical efficacy of various agents in GIST. ${ }^{43}$ Importantly, 26 showed potent growth inhibitory activity in these cell lines with no activity in the parental cell, demonstrating an ability to penetrate cells and inhibit the targets of interest. The relative potency in cells in the order PDGFR $\alpha$ $>$ PDGFR $\beta>$ c-KIT mirrors the ranking from enzyme assays and in comparison to acrylamide 25, 26 does not show any activity in the parental line, suggestive of fewer off target effects for the new warhead when compared to acrylamide.

\section{CONCLUSION}

Acrylamides are the backbone of approaches to target nucleophilic cysteines in both chemical biology and drug discovery. Recently reported alternatives such allenes or haloacylamides generally suffer from high reactivity, instability and incompatibility with biological systems. Exploration of reactive heterocycles has identified alkynyl benzoxazine and dihydroquinazoline motifs capable of electrophilic cysteine capture, which hold potential application as chemical biological probes and as warheads in drug molecules. We have successfully demonstrated the utility of these new moieties through site-selective protein modification of both C2Am and a HER-2 nanobody as well as their application in kinase drug scaffolds. Although iterative optimization against a particular target was not the focus of this work, alteration of the osimertinib scaffold led to the identification of a potent JAK3 inhibitor with enhanced selectivity across the kinome, high cellular selectivity across the cysteinome and improved in vitro pharmacokinetic profile relative to the related acrylamide-based covalent inhibitor. Covalent bond formation was demonstrated through kinase inhibition at high concentrations of ATP and confirmed by MS analysis following incubation with protein. Moreover, incorporation of a novel warhead into a c-KIT scaffold promoted formation of a covalent interaction with the target where acrylamide had previously failed, confirmed by X-ray structure determination. This scaffold was also found to be highly potent against PDGFR with a suggested covalent mode of action and demonstrated potent cell activity with fewer off target effects than the corresponding acrylamide. Overall, the novel warheads have a desirable reactivity and stability profile, are easily accessed synthetically and have the ability to reach vectors that acrylamides cannot. We therefore anticipate that these new moieties will be complimentary to acrylamides and have the potential for widespread use in future cysteine targeting covalent inhibitors.

\section{ASSOCIATED CONTENT}

Supporting Information. Experimental methods, compound characterization and associated data. This material is available free of charge via the Internet at http://pubs.acs.org.

\section{AUTHOR INFORMATION}

\section{Corresponding Authors}

*jason.kettle@astrazeneca.com

*k.mcaulay@beatson.gla.ac.uk

\section{Present Addresses}

$\nabla$ M.T: Department of Chemistry, University of Cambridge, Cambridge, CB2 1EW, UK

${ }^{\perp}$ D.J.O: Peak Proteins Ltd., 3G48 Mereside, Alderley Park, Macclesfield, Cheshire, SK10 4TG, UK

${ }^{\circledR}$ Drug Discovery Unit, CRUK Beatson Institute, Glasgow, UK, G61 1BD 


\section{ORCID}

Kirsten McAulay: 0000-0003-1864-7665

Jason G. Kettle: 0000-0001-7373-0758

Michael J. Waring: 0000-0002-9110-8783

Gonçalo J. L. Bernardes: 0000-0001-6594-8917

\section{Author Contributions}

All authors have given approval to the final version of the manuscript.

\section{ACKNOWLEDGMENT}

The authors would like to acknowledge funding from the AstraZeneca postdoctoral scheme for KM. We would also like to acknowledge the award of a Herchel Smith Fellowship studentship from Williams College for EAH and Royal Society University Research Fellowship for GJLB. We thank Ross C. Overman for preparation of the c-KIT and KDR protein used for crystallization. We also thank Dr André Neves and Prof. Kevin Brindle (CRUK Cambridge Institute, UK) for providing the C2Am protein and Dr S. Massa and Prof N. Devoogdt (Vrije Universiteit Brussel, Brussels) for the generous gift of the HER2-targeting nanobody 2Rb17c.

\section{ABBREVIATIONS}

ADC, antibody drug conjugate; ADMET, absorption distribution metabolism and excretion; BLK, B lymphocyte kinase; BMX, bone marrow kinase on chromosome X; BTK, Bruton's tyrosine kinase; EGFR, epidermal growth factor receptor; GIST, gastrointestinal stromal tumors; GSH, glutathione; HER2, human epidermal growth factor receptor 2; hERG, human ether-a-go-go-related gene; hu heps, human hepatocytes; hu mics, human microsomes; JAK, Janus kinase; KDR, kinase insert domain receptor; $\mathrm{NaP}_{\mathrm{i}}$, sodium phosphate buffer; PDGFR, plateletderived growth factor receptor; KRAS, Kirsten rat sarcoma; PPB, plasma protein binding; SAR, structure activity relationship; TCEP, tris(2carboxyethyl)phosphine; TCI, targeted covalent inhibitor; TYK2, tyrosine kinase 2.

\section{REFERENCES}

1. Lonsdale, R.; Ward, R. A., Structure-based design of targeted covalent inhibitors. Chem. Soc. Rev. 2018, 47 (11), $3816-3830$.

2. Singh, J.; Petter, R. C.; Baillie, T. A.; Whitty, A., The resurgence of covalent drugs. Nature Rev. Drug Discov. $2011,10,307$.

3. Zhao, Z.; Bourne, P. E., Progress with covalent small-molecule kinase inhibitors. Drug Discov. Today 2018,23 (3), $727-735$.

4. Liu, Q.; Sabnis, Y.; Zhao, Z.; Zhang, T.; Buhrlage, S. J.; Jones, Lyn H.; Gray, N. S., Developing Irreversible Inhibitors of the Protein Kinase Cysteinome. Chem. Biol. 2013, 20 (2), 146-159.

5. Zhang, J.; Yang, P. L.; Gray, N. S., Targeting cancer with small molecule kinase inhibitors. Nature Rev. Cancer 2009, 9 , 28-39.

6. Zhao, Z.; Liu, Q.; Bliven, S.; Xie, L.; Bourne, P. E., Determining Cysteines Available for Covalent Inhibition Across the Human Kinome. J. Med. Chem. 2017, 60 (7), 2879-2889.

7. Boran, A. D. W.; Lyengar, R., Systems approaches to polypharmacology and drug discovery. Curr. Opin. Drug Discov. Devel. 2010, 13 (3), 297-309.

8. Barf, T.; Kaptein, A., Irreversible Protein Kinase Inhibitors: Balancing the Benefits and Risks. J. Med. Chem. 2012, 55 (14), $6243-$ 6262. 
9. Bauer, R. A., Covalent inhibitors in drug discovery: from accidental discoveries to avoided liabilities and designed therapies. Drug Discov. Today 2015, 20 (9), 1061-1073.

10. Butterworth, S.; Cross, D. A. E.; Finlay, M. R. V.; Ward, R. A.; Waring, M. J., The structure-guided discovery of osimertinib: the first U.S. FDA approved mutant selective inhibitor of EGFR T790M. MedChemComm 2017, 8 (5), 820-822.

11. Barf, T.; Covey, T.; Izumi, R.; van de Kar, B.; Gulrajani, M.; van Lith, B.; van Hoek, M.; de Zwart, E.; Mittag, D.; Demont, D.; Verkaik, S.; Krantz, F.; Pearson, P. G.; Ulrich, R.; Kaptein, A., Acalabrutinib (ACP-196): A covalent Bruton tyrosine kinase (BTK) inhibitor with a differentiated selectivity and in vivo potency profile. J. Pharmacol Exp. Ther. 2017, 363 (2), $240-252$.

12. Baillie, T. A., Targeted Covalent Inhibitors for Drug Design. Angew. Chem. Int. Ed. 2016,55 (43), 13408-13421.

13. Chaikuad, A.; Koch, P.; Laufer, S. A.; Knapp, S., The Cysteinome of Protein Kinases as a Target in Drug Development. Angew. Chem. Int. Ed. 2018, 57 (16), 4372-4385.

14. Jackson, P. A.; Widen, J. C.; Harki, D. A.; Brummond, K. M., Covalent Modifiers: A Chemical Perspective on the Reactivity of $\alpha, \beta$-Unsaturated Carbonyls with Thiols via Hetero-Michael Addition Reactions. J. Med. Chem. 2017, 60 (3), $839-885$.

15. Song, Z.; Ge, Y.; Wang, C.; Huang, S.; Shu, X.; Liu, K.; Zhou, Y.; Ma, X., Challenges and Perspectives on the Development of Small-Molecule EGFR Inhibitors against T790M-Mediated Resistance in Non-Small-Cell Lung Cancer. J. Med. Chem. 2016, 59 (14), 6580-6594.

16. Chen, D.; Guo, D.; Yan, Z.; Zhao, Y., Allenamide as a bioisostere of acrylamide in the design and synthesis of targeted covalent inhibitors. MedChemComm 2018, 9 (2), 244-253.

17. Mons, E.; Jansen, I. D. C.; Loboda, J.; van Doodewaerd, B. R.; Hermans, J.; Verdoes, M.; van Boeckel, C. A. A.; van Veelen, P. A.; Turk, B.; Turk, D.; Ovaa, H., The Alkyne Moiety as a Latent Electrophile in Irreversible Covalent Small Molecule Inhibitors of Cathepsin K. J. Am. Chem. Soc. 2019, 141 (8), 3507-3514.

18. Nakagawa, Y.; Sawaki, Y.; Kimura, T.; Tomura, T.; Igarashi, Y.; Ojika, M., Quinocidin, a Cytotoxic Antibiotic with an Unusual 3,4-Dihydroquinolizinium Ring and Michael Acceptor Reactivity toward Thiols. Chem. Eur. 2017, 23 (71), 17894-17897.

19. Xu, Y.; Cuccui, J.; Denman, C.; Maharjan, T.; Wren, B. W.; Wagner, G. K., Structure-activity relationships in a new class of nonsubstrate-like covalent inhibitors of the bacterial glycosyltransferase LgtC. Bioorg. Med. Chem. 2018, 26 (11), $2973-2983$.

20. Keeley, A.; Ábrányi-Balogh, P.; Keserü, G. M., Design and characterization of a heterocyclic electrophilic fragment library for the discovery of cysteine-targeted covalent inhibitors. MedChemComm 2019, 10 (2), 263-267.

21. Gehringer, M.; Laufer, S. A., Emerging and Re-Emerging Warheads for Targeted Covalent Inhibitors: Applications in Medicinal Chemistry and Chemical Biology. J. Med. Chem. 2019, 62 (12), 5673-5724.

22. Krall, N.; da Cruz, F. P.; Boutureira, O.; Bernardes, G. J. L., Site-selective protein-modification chemistry for basic biology and drug development. Nature Chem. 2015, 8, 103-113.

23. Hoyt, E. A.; Cal, P. M. S. D.; Oliveira, B. L.; Bernardes, G. J. L., Contemporary approaches to site-selective protein modification. Nature Rev. Chem. 2019, 3 (3), 147-171.

24. Beck, A.; Goetsch, L.; Dumontet, C.; Corvaïa, N., Strategies and challenges for the next generation of antibody-drug conjugates. Nature Rev. Drug Discov. 2017, 16, 315-337. 
25. Bernardim, B.; Cal, P. M. S. D.; Matos, M. J.; Oliveira, B. L.; Martínez-Sáez, N.; Albuquerque, I. S.; Perkins, E.; Corzana, F.; Burtoloso, A. C. B.; Jiménez-Osés, G.; Bernardes, G. J. L., Stoichiometric and irreversible cysteine-selective protein modification using carbonylacrylic reagents. Nature Commun. 2016, 7, 13128.

26. Matos, M. J.; Navo, C. D.; Hakala, T.; Ferhati, X.; Guerreiro, A.; Hartmann, D.; Bernardim, B.; Saar, K. L.; Compañón, I.; Corzana, F.; Knowles, T. P. J.; Jiménez-Osés, G.; Bernardes, G. J. L., Quaternization of Vinyl/Alkynyl Pyridine Enables Ultrafast Cysteine-Selective Protein Modification and Charge Modulation. Angew. Chem. Int. Ed. 2019, 58 (20), 6640-6644.

27. Walsh, S. J.; Omarjee, S.; Galloway, W. R. J. D.; Kwan, T. T. L.; Sore, H. F.; Parker, J. S.; Hyvönen, M.; Carroll, J. S.; Spring, D. R., A general approach for the site-selective modification of native proteins, enabling the generation of stable and functional antibody-drug conjugates. Chem. Sci. 2019, 10 (3), 694-700.

28. Lonsdale, R.; Burgess, J.; Colclough, N.; Davies, N. L.; Lenz, E. M.; Orton, A. L.; Ward, R. A., Expanding the Armory: Predicting and Tuning Covalent Warhead Reactivity. J. Chem. Inf. Model. 2017, 57 (12), 3124-3137.

29. Cee, V. J.; Volak, L. P.; Chen, Y.; Bartberger, M. D.; Tegley, C.; Arvedson, T.; McCarter, J.; Tasker, A. S.; Fotsch, C., Systematic Study of the Glutathione (GSH) Reactivity of N-Arylacrylamides: 1. Effects of Aryl Substitution. J. Med. Chem. 2015, 58 (23), 91719178.

30. Flanagan, M. E.; Abramite, J. A.; Anderson, D. P.; Aulabaugh, A.; Dahal, U. P.; Gilbert, A. M.; Li, C.; Montgomery, J.; Oppenheimer, S. R.; Ryder, T.; Schuff, B. P.; Uccello, D. P.; Walker, G. S.; Wu, Y.; Brown, M. F.; Chen, J. M.; Hayward, M. M.; Noe, M. C.; Obach, R. S.; Philippe, L.; Shanmugasundaram, V.; Shapiro, M. J.; Starr, J.; Stroh, J.; Che, Y., Chemical and Computational Methods for the Characterization of Covalent Reactive Groups for the Prospective Design of Irreversible Inhibitors. J. Med. Chem. 2014, 57 (23), 10072-10079.

31. Voice, A.; Tresadern, G.; van Vlijmen, H.; Mulholland, A., Limitations of Ligand-Only Approaches for Predicting the Reactivity of Covalent Inhibitors. J. Chem. Inf. Model. 2019, 59 (10), 4220-4227.

32. Wissner, A.; Overbeek, E.; Reich, M. F.; Floyd, M. B.; Johnson, B. D.; Mamuya, N.; Rosfjord, E. C.; Discafani, C.; Davis, R.; Shi, X.; Rabindran, S. K.; Gruber, B. C.; Ye, F.; Hallett, W. A.; Nilakantan, R.; Shen, R.; Wang, Y.-F.; Greenberger, L. M.; Tsou, H.-R., Synthesis and Structure-Activity Relationships of 6,7-Disubstituted 4-Anilinoquinoline-3-carbonitriles. The Design of an Orally Active, Irreversible Inhibitor of the Tyrosine Kinase Activity of the Epidermal Growth Factor Receptor (EGFR) and the Human Epidermal Growth Factor Receptor-2 (HER-2). J. Med. Chem. 2003, 46 (1), 49-63.

33. Tsou, H.-R.; Mamuya, N.; Johnson, B. D.; Reich, M. F.; Gruber, B. C.; Ye, F.; Nilakantan, R.; Shen, R.; Discafani, C.; DeBlanc, R.; Davis, R.; Koehn, F. E.; Greenberger, L. M.; Wang, Y.-F.; Wissner, A., 6-Substituted-4-(3-bromophenylamino)quinazolines as Putative Irreversible Inhibitors of the Epidermal Growth Factor Receptor (EGFR) and Human Epidermal Growth Factor Receptor (HER-2) Tyrosine Kinases with Enhanced Antitumor Activity. J. Med. Chem. 2001, 44 (17), 2719-2734.

34. Lebraud, H.; Coxon, C. R.; Archard, V. S.; Bawn, C. M.; Carbain, B.; Matheson, C. J.; Turner, D. M.; Cano, C.; Griffin, R. J.; Hardcastle, I. R.; Baisch, U.; Harrington, R. W.; Golding, B. T., Model system for irreversible inhibition of Nek2: thiol addition to ethynylpurines and related substituted heterocycles. Org. Biomol. Chem. 2014, 12 (1), 141-148.

35. Vaneycken, I.; Devoogdt, N.; Gassen, N. V.; Vincke, C.; Xavier, C.; Wernery, U.; Muyldermans, S.; Lahoutte, T.; Caveliers, V., Preclinical screening of anti-HER2 nanobodies for molecular imaging of breast cancer. FASEB J. 2011, 25 (7), $2433-2446$. 
36. Stenton, B. J.; Oliveira, B. L.; Matos, M. J.; Sinatra, L.; Bernardes, G. J. L., A thioether-directed palladium-cleavable linker for targeted bioorthogonal drug decaging. Chem. Sci. 2018, 9 (17), 4185-4189.

37. Ravasco, J. M. J. M.; Faustino, H.; Trindade, A.; Gois, P. M. P., Bioconjugation with Maleimides: A Useful Tool for Chemical Biology. Chem. Eur. 2019, 25 (1), 43-59.

38. Finlay, M. R. V.; Anderton, M.; Ashton, S.; Ballard, P.; Bethel, P. A.; Box, M. R.; Bradbury, R. H.; Brown, S. J.; Butterworth, S.; Campbell, A.; Chorley, C.; Colclough, N.; Cross, D. A. E.; Currie, G. S.; Grist, M.; Hassall, L.; Hill, G. B.; James, D.; James, M.; Kemmitt, P.; Klinowska, T.; Lamont, G.; Lamont, S. G.; Martin, N.; McFarland, H. L.; Mellor, M. J.; Orme, J. P.; Perkins, D.; Perkins, P.; Richmond, G.; Smith, P.; Ward, R. A.; Waring, M. J.; Whittaker, D.; Wells, S.; Wrigley, G. L., Discovery of a Potent and Selective EGFR Inhibitor (AZD9291) of Both Sensitizing and T790M Resistance Mutations That Spares the Wild Type Form of the Receptor. J. Med. Chem. 2014, 57 (20), 8249-8267.

39. Ghoreschi, K.; Laurence, A.; O’Shea, J. J., Janus kinases in immune cell signalling. Immunol. Rev. 2009,228 (1), $273-287$.

40. Forster, M.; Gehringer, M.; Laufer, S. A., Recent advances in JAK3 inhibition: Isoform selectivity by covalent cysteine targeting. Bioorg. Med. Chem. Lett. 2017, 27 (18), 4229-4237.

41. Elwood, F.; Witter, D. J.; Piesvaux, J.; Kraybill, B.; Bays, N.; Alpert, C.; Goldenblatt, P.; Qu, Y.; Ivanovska, I.; Lee, H.-H.; Chiu, C.-S.; Tang, H.; Scott, M. E.; Deshmukh, S. V.; Zielstorff, M.; Byford, A.; Chakravarthy, K.; Dorosh, L.; Rivkin, A.; Klappenbach, J.; Pan, B.-S.; Kariv, I.; Dinsmore, C.; Slipetz, D.; Dandliker, P. J., Evaluation of JAK3 Biology in Autoimmune Disease Using a Highly Selective, Irreversible JAK3 Inhibitor. J. Pharmacol. Exp. Ther. 2017, 361 (2), 229-244.

42. Abbaspour Babaei, M.; Kamalidehghan, B.; Saleem, M.; Huri, H. Z.; Ahmadipour, F., Receptor tyrosine kinase (c-Kit) inhibitors: a potential therapeutic target in cancer cells. Drug Des. Devel. Ther. 2016, 10, 2443-2459.

43. Kettle, J. G.; Anjum, R.; Barry, E.; Bhavsar, D.; Brown, C.; Boyd, S.; Campbell, A.; Goldberg, K.; Grondine, M.; Guichard, S.; Hardy, C. J.; Hunt, T.; Jones, R. D. O.; Li, X.; Moleva, O.; Ogg, D.; Overman, R. C.; Packer, M. J.; Pearson, S.; Schimpl, M.; Shao, W.; Smith, A.; Smith, J. M.; Stead, D.; Stokes, S.; Tucker, M.; Ye, Y., Discovery of N-(4-\{[5-Fluoro-7-(2-methoxyethoxy)quinazolin4-yl]amino\}phenyl)-2-[4-(propan-2-yl)-1H-1,2,3-triazol-1-yl]acetamide (AZD3229), a Potent Pan-KIT Mutant Inhibitor for the Treatment of Gastrointestinal Stromal Tumors. J. Med. Chem. 2018, 61 (19), 8797-8810.

44. Jung, F. H.; Morgentin, R. R.; Ple, P., Quinoline derivatives as platelet-derived growth factor inhibitors, their preparation, pharmaceutical compositions, and use in the treatment of cancer. PCT Int. Appl. (2007), WO2007099323.

45. Awoonor-Williams, E.; Rowley, C. N., How Reactive are Druggable Cysteines in Protein Kinases? J. Chem. Inf. Model. 2018, $58(9), 1935-1946$.

46. Leproult, E.; Barluenga, S.; Moras, D.; Wurtz, J.-M.; Winssinger, N., Cysteine Mapping in Conformationally Distinct Kinase Nucleotide Binding Sites: Application to the Design of Selective Covalent Inhibitors. J. Med. Chem. 2011, 54 (5), $1347-1355$.

47. Qiu, F. H.; Ray, P.; Brown, K.; Barker, P. E.; Jhanwar, S.; Ruddle, F. H.; Besmer, P., Primary structure of c-kit: relationship with the CSF-1/PDGF receptor kinase family-oncogenic activation of v-kit involves deletion of extracellular domain and C terminus. EMBO J. 1988, 7 (4), 1003-1011.

48. Chen, P.-H.; Chen, X.; He, X., Platelet-derived growth factors and their receptors: Structural and functional perspectives. BBAProteins Proteom. 2013, 1834 (10), 2176-2186. 
49. Hantschel, O.; Rix, U.; Superti-Furga, G., Target spectrum of the BCR-ABL inhibitors imatinib, nilotinib and dasatinib. Leukemia Lymphoma 2008, 49 (4), 615-619.

50. Song, L.; Rawal, B.; Nemeth, J. A.; Haura, E. B., JAK1 Activates STAT3 Activity in Non-Small-Cell Lung Cancer cells and IL6 Neutralizing Antibodies can Suppress JAK1-STAT3 Signaling. Mol. Cancer Ther. 2011, 10 (3), 481-494.

51. Kettle, J. G.; Bagal, S. K.; Bickerton, S.; Bodnarchuk, M. S.; Breed, J.; Carbajo, R. J.; Cassar, D. J.; Chakraborty, A.; Cosulich, S.; Cumming, I.; Davies, M.; Eatherton, A.; Evans, L.; Feron, L.; Fillery, S.; Gleave, E. S.; Goldberg, F. W.; Harlfinger, S.; Hanson, L.; Howard, M.; Howells, R.; Jackson, A.; Kemmitt, P.; Kingston, J. K.; Lamont, S.; Lewis, H. J.; Li, S.; Liu, L.; Ogg, D.; Phillips, C.; Polanski, R.; Robb, G.; Robinson, D.; Ross, S.; Smith, J. M.; Tonge, M.; Whiteley, R.; Yang, J.; Zhang, L.; Zhao, X. StructureBased Design and Pharmacokinetic Optimization of Covalent Allosteric Inhibitors of the Mutant GTPase KRASG12C. J. Med. Chem. Articles ASAP. DOI: 10.1021/acs.jmedchem.9b01720.

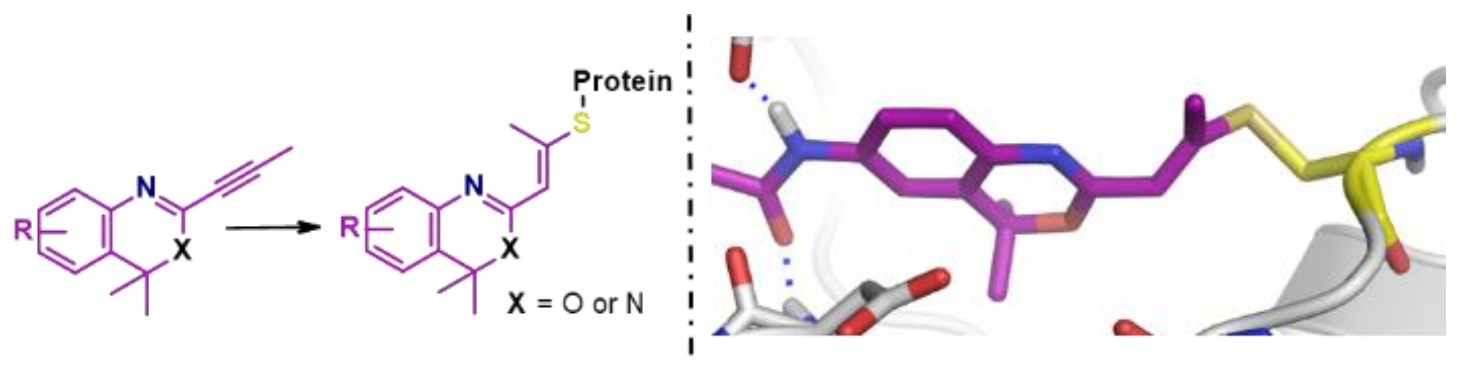

For Table of Contents Only 